\title{
Fischer-Tropsch Synthesis Product Selectivity over an Industrial Iron-based Catalyst: Effect of Process Conditions
}

Branislav Todic ${ }^{1,2}$, Lech Nowicki ${ }^{3}$, Nikola Nikacevic ${ }^{2}$ and Dragomir B. Bukur*, 1, 4

${ }^{1}$ Chemical Engineering Program, Texas A\&M University at Qatar, PO Box 23874, Doha, Qatar

${ }^{2}$ Faculty of Technology and Metallurgy, University of Belgrade, Karnegijeva 4, Belgrade, Serbia

${ }^{3}$ Lodz University of Technology, Faculty of Process and Environmental Engineering, Wolczanska 213, 90-924 Lodz, Poland

${ }^{4}$ Texas A\&M University, 3122 TAMU, College Station, Texas 77843, United States

*Tel.: +974-4423-0134. Fax: +974-4423-0065. Email: dragomir.bukur@qatar.tamu.edu 


\begin{abstract}
The effect of process conditions on product selectivity of Fischer-Tropsch Synthesis (FTS) over industrial iron-based catalyst $\left(100 \mathrm{Fe} / 5 \mathrm{Cu} / 4.2 \mathrm{~K} / 25 \mathrm{SiO}_{2}\right)$ was studied in a 1-L stirred tank slurry reactor. Experiments were performed over a range of different reaction conditions, including three temperatures $(\mathrm{T}=493,513$ and $533 \mathrm{~K})$, four pressures $(\mathrm{P}=0.8,1.5,2.25$ and 2.5 $\mathrm{MPa})$, two synthesis gas feed molar ratios $\left(\mathrm{H}_{2} / \mathrm{CO}=0.67\right.$ and 2$)$ and gas space velocity from 0.52 to $23.5 \mathrm{Ndm}^{3} / \mathrm{g}-\mathrm{Fe} / \mathrm{h}$. The effect of process conditions on reaction pathways of FTS and secondary 1-olefin reactions was analyzed by comparing product selectivities, chain growth probabilities and ratios of main products (n-paraffin, 1- and 2-olefin). Reduction of methane production and increase of $\mathrm{C}_{5+}$ products was achieved by decreasing temperature, inlet $\mathrm{H}_{2} / \mathrm{CO}$ ratio and/or increasing pressure. Overall selectivity towards methane and $\mathrm{C}_{5+}$ did not show significant changes with variations in residence time. All of the product selectivity variations were shown to be related to changes in chain length dependent growth probabilities.
\end{abstract}

Keywords: Fischer-Tropsch synthesis; slurry reactor; product selectivity; iron-catalyst; coal-toliquid. 


\section{Introduction}

Natural resources, such as coal, natural gas and biomass, can be converted into liquid hydrocarbon fuels via the Fischer-Tropsch Synthesis (FTS) reaction. FTS is a heterogeneous reaction first discovered in the early twentieth century [1]. Reactants, carbon monoxide and hydrogen, are converted to an array of long chain molecules, mainly consisting of n-paraffins and 1- and 2-olefins:

$$
\begin{array}{ll}
n \mathrm{CO}+(2 n+1) \mathrm{H}_{2} \rightarrow \mathrm{C}_{n} \mathrm{H}_{2 n+2}+n \mathrm{H}_{2} \mathrm{O} & n=1,2,3 \ldots \\
n \mathrm{CO}+2 n \mathrm{H}_{2} \rightarrow \mathrm{C}_{n} \mathrm{H}_{2 n}+n \mathrm{H}_{2} \mathrm{O} & n=2,3,4 \ldots
\end{array}
$$

The main advantage of such synthetic fuel mixtures is their purity compared to conventional oil-derived fuels, since they do not contain nitrogen, sulfur nor aromatic compounds. These environmental, as well as economic, reasons have led to the intensification of research into FTS technology during the last two decades.

The catalysts of choice for industrial FTS are cobalt and iron. If the raw material is coal, then the preferred catalyst is usually iron [2, 3]. One of the main features of iron FTS catalysts is their water-gas-shift (WGS) activity. WGS reaction can be presented as:

$$
\mathrm{CO}+\mathrm{H}_{2} \mathrm{O} \leftrightarrow \mathrm{CO}_{2}+\mathrm{H}_{2}
$$

The WGS reaction provides additional hydrogen for FTS, which is needed in the case of coal-derived syngas. Coal-derived syngas has a $\mathrm{H}_{2} / \mathrm{CO}$ ratio below 2, the latter being an approximate stoichiometric $\mathrm{H}_{2} / \mathrm{CO}$ ratio needed to produce hydrocarbons according to equations (1) and (2).

The exact sequence of elementary steps in FTS is still under debate [4, 5]. It is, however, generally accepted that FTS follows a polymerization type mechanism. The products can be 
described by the Anderson-Schulz-Flory (ASF) model [6], where the molecular mass distribution is governed by a chain growth probability factor $(\alpha)$. The ASF model typically provides a good description of the product distribution in the low carbon range (below $\mathrm{C}_{10}$ ), while the higher carbon number products deviate and are present in an amount higher than predicted by the ASF distribution model. This is because $\alpha$ does not have a constant value, but in fact increases with carbon number from $\mathrm{C}_{3}$ before reaching an asymptotic value at higher carbon number range (typically above $\mathrm{C}_{15}$ ) [7]. Typical deviations from the ASF distribution include higher methane and lower $C_{2}[8,9]$. Another important feature of FTS products is the ratio between various main products (n-paraffin/1-olefin and 2-olefin/total olefin). The 1-olefin/n-paraffin ratio decreases exponentially for $\mathrm{C}_{3}+$ hydrocarbons, whereas the amount of 2-olefin in total olefin of the same carbon number increases with carbon number. Ratios of hydrocarbon products are particularly important in studies of the 1-olefin secondary reactions (e.g. hydrogenation to n-paraffin, isomerization to 2-olefin, readsorption and continued chain growth [10-12]).

The delicate interplay between the kinetics of various parallel reactions (FTS, WGS and olefin secondary reactions), at different process conditions, determines the overall selectivity of FTS products. One of the main goals in FTS is to achieve high selectivity of desired $\mathrm{C}_{5+}$ products and reduce methane selectivity. Proper selection of process conditions is important in achieving this goal. Even though there is number of studies and reviews describing how variation of each process parameter (temperature, pressure, reactant feed ratio and conversion level) affects overall FTS selectivity [8, 13-18], the understanding of reasons for the observed behaviors is still incomplete. Catalyst composition, in particular its potassium content, plays a crucial role in determining the FTS product distribution and how it changes with process conditions [15,16,1921]. 
Here we present results from experiments in a stirred tank slurry reactor obtained over a wide range of process conditions using Ruhrchemie catalyst $\left(\mathrm{Fe} / \mathrm{Cu} / \mathrm{K} / \mathrm{SiO}_{2}\right)$, and analyze the effect of process conditions on hydrocarbon product distribution, chain growth probability, oxygenates and olefin selectivities. This is an extension of our work with the Ruhrchemie catalyst [14] both in terms of the range of process conditions employed and data analysis. Based on these results, some qualitative conclusions are drawn about reaction pathways and kinetics of primary FTS reactions, and secondary 1-olefin reactions.

This paper is dedicated to Professor Bartholomew who has made significant contributions to advancement of our knowledge about various aspects of FTS [22-26].

\section{Experimental}

\subsection{Catalyst preparation and activation}

Commercial precipitated iron FTS catalyst obtained from Ruhrchemie AG (OberhausenHolten, Germany) was used in this study. This catalyst (designated as LP 33/81) was used initially in fixed-bed reactors at Sasol in South Africa and its preparation procedure was described by Frohning et al. [27]. Its nominal composition is $100 \mathrm{Fe} / 5 \mathrm{Cu} / 4.2 \mathrm{~K} / 25 \mathrm{SiO}_{2}$ (in parts by weight). The catalyst (11-25 g) was calcined in air at $300^{\circ} \mathrm{C}$ and a sample with a size fraction

between 140 and 325 mesh (44 - $105 \mu \mathrm{m})$ was loaded into the reactor filled with 300-320 g of Durasyn 164 oil (a hydrogenated 1-decene homopolymer, $\mathrm{C}_{30}$ obtained from Albermarle Co.). The catalyst was pretreated in $\mathrm{CO}$ at $280^{\circ} \mathrm{C}, 0.8 \mathrm{MPa}$, and $3 \mathrm{NL} / \mathrm{g}$-cat/h (where, NL/h, denotes volumetric gas flow rate at $0^{\circ} \mathrm{C}$ and 1 bar) for 12 hours.

\subsection{Reactor system and operating procedures}


Three tests (runs 1, 2 and 3) were conducted in a $1 \mathrm{dm}^{3}$ stirred tank slurry reactor (Autoclave Engineers). Schematic of slurry reactor system is shown in Figure 1. The feed gas flow rate was adjusted with a mass flow controller and passed through a series of oxygen removal, alumina and activated charcoal traps to remove trace impurities. In the present study a premixed synthesis gas mixtures of desired $\mathrm{H}_{2} / \mathrm{CO}$ ratios were used. After leaving the reactor, the exit gas passed through a series of high and low (ambient) pressure traps to condense liquid products. High molecular weight hydrocarbons (wax), withdrawn from a slurry reactor through a porous cylindrical sintered metal filter, and liquid products, collected in the high and low pressure traps, were analyzed by capillary gas chromatography. Liquid products collected in the high and atmospheric pressure traps were first separated into an organic phase and an aqueous phase and then analyzed using different columns and temperature programmed methods. The reactants and noncondensible products leaving the ice traps were analyzed on an on-line GC (Carle AGC 400) with multiple columns using both flame ionization and thermal conductivity detectors. Stirring speed of 1200 rpm was used to minimize external mass transfer resistance. Further details on the experimental set up, operating procedures and product quantification can be found elsewhere [14, 28].

After the pretreatment the catalyst was tested initially at $260^{\circ} \mathrm{C}, 1.5 \mathrm{MPa}, 4 \mathrm{NL} / \mathrm{g}-\mathrm{Fe} / \mathrm{h}$ using CO rich synthesis gas $\left(\mathrm{H}_{2} / \mathrm{CO}\right.$ molar feed ratio of 0.67$)$. After approaching a steady state ( $\sim 60 \mathrm{~h}$ on stream) the catalyst was tested at different process conditions (total of 25 sets of process conditions in three tests/runs). The minimum length of time between changes in process conditions was $20 \mathrm{~h}$.

\subsection{Experimental data}


In total 25 sets of data at different process conditions were obtained in three separate runs (with two replicates of baseline process conditions), involving 12, 7 and 8 mass balances, respectively. The conditions and selected results are summarized in Table 1. Data were obtained at three reaction temperatures $(\mathrm{T}=493,513$ and $533 \mathrm{~K})$, four pressures $(\mathrm{P}=0.8,1.5,2.25$ and 2.5 MPa), and two synthesis gas feed molar ratios $\left(\mathrm{H}_{2} / \mathrm{CO}=0.67\right.$ representative of coal derived synthesis gas and $\mathrm{H}_{2} / \mathrm{CO}=2$ representative of syngas from natural gas). The gas space velocity (SV) was varied from 0.52 to $23.5 \mathrm{Ndm}^{3} / \mathrm{g}$-Fe/h to obtain a wide range of conversions ( $\mathrm{X}_{\mathrm{CO}}=9$ to $84 \%)$.

Following formulas were used to calculate conversions and selectivities:

- $\quad$ CO conversion (\% by moles)

$$
X_{C O}=100 \% \times \frac{(\text { Moles of CO at inlet })-(\text { Moles of CO at outlet })}{(\text { Moles of CO at inlet })}
$$

- $\quad \mathrm{CO}_{2}$ selectivity (\% by moles)

$$
S_{\mathrm{CO}_{2}}=100 \% \times \frac{\text { Moles of } \mathrm{CO}_{2} \text { at outlet }}{(\text { Moles of CO at inlet })-(\text { Moles of CO at outlet })}
$$

- $\quad \mathrm{C}_{\mathrm{n}}$ selectivity (\% by mass in hydrocarbons)

$$
S_{C n}=100 \% \times \frac{\dot{m}_{C_{n}}}{\dot{m}_{H C, \text { total }}}
$$

where $\dot{m}_{C_{n}}$ is the mass flowrate of hydrocarbons with $\mathrm{n}$ carbon atoms.

- $\mathrm{C}_{5}{ }^{+}$selectivity (\% by mass in hydrocarbons)

$$
S_{C_{5+}}=100 \%-\sum_{n=1}^{4} S_{C n}
$$


- Selectivity can also be expressed in C-atom \% basis, which is especially useful when only gas phase analysis is performed (i.e. no liquid samples are collected).

$$
S_{C n}=100 \% \times \frac{\mathrm{n} \times \text { Moles of } \mathrm{C}_{\mathrm{n}} \text { at outlet }}{(\text { Moles of CO at inlet })-(\text { Moles of } \mathrm{CO} \text { at outlet })-\left(\text { Moles of } \mathrm{CO}_{2} \text { at outlet }\right)}
$$

where $n=1-4$. The selectivity to $C_{5+}$ is then expressed as:

$$
S_{C_{5+}}=100 \%-\sum_{n=1}^{4} S_{C n}
$$

The above formulas assume that there is no carbon dioxide in the feed.

- Mole fractions of hydrocarbons (product distribution) with $\mathrm{n}$ carbon atoms

$$
y_{n}=\frac{F_{n}}{F_{H C, t o t}}
$$

where $F_{n}$ is the molar flowrate of hydrocarbons with $n$ carbon number and $F_{H C \text {,tot }}$ is the flowrate of all hydrocarbons.

The chain growth probabilities for hydrocarbons having $n$ carbon atoms $\left(\alpha_{n}\right)$ were calculated as:

$$
\alpha_{n}=\frac{\sum_{i=n+1}^{\infty} F_{i}}{\sum_{i=n}^{\infty} F_{i}}
$$

1-olefin to n-paraffin and 2-olefin to total olefin ratios for different chain lengths were calculated as follows:

$$
1-\text { olefin } / n-\text { paraffin }=\frac{F_{n}^{1-o l e f i n}}{F_{n}^{n-p a r a f f i n}}
$$




$$
2-\text { olefin } / \text { total olefin }=\frac{F_{n}^{2-o l e f i n}}{F_{n}^{\text {olefin }}}
$$

\section{Results and discussion}

Analyzing the effect of process conditions (temperature, pressure, reactant feed ratio and conversion level) on FTS product formation selectivity over Fe-based catalyst is complex because of the competing effects of several parallel reactions, including primary FTS reaction, secondary 1-olefin reactions and WGS. Apparent product distribution features, such as growth probabilities, 1-olefin-to-n-paraffin ratios and selectivities with carbon number, are dependent on the mutual interplay of the kinetics of these reactions. With Fe-based catalysts the effect of WGS is very significant. This reaction affects concentrations (partial pressures) of $\mathrm{CO}, \mathrm{H}_{2}, \mathrm{CO}_{2}$ and $\mathrm{H}_{2} \mathrm{O}$ in the system, which in turn has an impact on kinetics of both primary FTS and 1-olefin secondary reactions.

Because of this complexity and unknown nature of kinetics over Fe-based catalysts, it is impossible to design an experiment in which only one process parameter affecting kinetics is

varied, while all others are kept constant. The observed FTS behavior will therefore reflect a lumped effect of several process parameters (e.g. increasing $\mathrm{T}$ and changing partial pressures of reactants). Dry $[13,29]$ has shown that FTS selectivity correlates well with $\mathrm{H}_{2} / \mathrm{CO}$ ratio in the reactor for low temperature FTS (LTFT) at Sasol. Therefore, when assessing the effect of process conditions on selectivities it is important to make comparisons at nearly constant values of this ratio in the reactor.

\subsection{Effect of time on stream on catalyst activity and selectivity}


The catalyst was tested initially at baseline conditions (533 K, $1.5 \mathrm{MPa}, 4 \mathrm{NL} / \mathrm{g}-\mathrm{Fe} / \mathrm{h}$, $\left.\mathrm{H}_{2} / \mathrm{CO}=0.67\right)$ in order to check reproducibility of data collected in three different runs. The catalyst in Runs 1 and 2 was tested at baseline conditions up to $80 \mathrm{~h}$ on stream, whereas in Run 3 from 50 to $73 \mathrm{~h}$ on stream. Results from all three tests at the baseline conditions and during the initial period are shown in Figure 2. CO conversion (Figure 2a), methane and $\mathrm{C}_{5+}$ hydrocarbon selectivities (Figure $2 \mathrm{~b}$ ) during the first $80 \mathrm{~h}$ of testing were very similar in all three tests. It was observed that conversion and selectivity approach stationary values after about $50-60 \mathrm{~h}$ on stream. Ruhrchemie catalyst was studied extensively in our laboratory [14, 28, 30-32], and it was found that selectivity does not change much after 50-60 h on stream, even though conversion may increase or decrease slightly with time (up to $100 \mathrm{~h}$ on stream) while maintaining constant process conditions. Small changes in conversion do not have significant effect on selectivity.

Baseline conditions were periodically repeated in all three runs in order to assess the extent of catalyst deactivation. $\mathrm{CO}$ conversion and selectivities at the baseline process conditions and different times on stream are shown in Figure 3. Catalyst activity (CO conversion) decreased with time in all three tests (Figure 3a). Methane and $\mathrm{C}_{5}{ }^{+}$selectivities were relatively constant with time (Figure 3b). In previous studies [14, 15, 33] it was found that methane and $\mathrm{C}_{5+}$ selectivity slowly increased and decreased, respectively, with time on stream (TOS). Also variation of product distribution as a function of carbon number with time was examined in Run 1 (mass balances 1, 7 and 10 in Table 1). Total hydrocarbon and 1-olefin/n-paraffin ratio for these conditions are shown in Figures $4 \mathrm{a}$ and $4 \mathrm{~b}$, respectfully. It can be seen that the product distribution did not change significantly with time. From this we conclude that data at other process conditions were not significantly affected by catalyst deactivation.

\subsection{Water-gas-shift reaction}


A measure of WGS activity is the amount of $\mathrm{CO}_{2}$ formed in the reactor. In order to be able to understand and at least partially eliminate the effect of WGS reaction on FTS product distribution we will first analyze how WGS activity varies with process conditions.

A useful property to look at when studying WGS is the usage ratio (UR):

$$
\mathrm{UR}=\left(\text { Moles of } \mathrm{H}_{2} \text { consumed }\right) /(\text { Moles of CO consumed })
$$

In the absence of the WGS reaction, the usage ratio is approximately 2 (Eqs. 1 and 2). In the case of high WGS activity, where all water produced by FTS is consumed by the WGS reaction, the usage ratio is 0.5 and the $\mathrm{CO}_{2}$ selectivity is $50 \%$ (assuming that $\mathrm{CO}$ is not consumed in any other reactions except hydrocarbon formation and WGS).

The effect of temperature and conversion of the limiting reactant $\left(\mathrm{H}_{2}\right.$ for $\mathrm{H}_{2} / \mathrm{CO}=0.67$ feed gas, $\mathrm{CO}$ for $\mathrm{H}_{2} / \mathrm{CO}=2$ feed gas) on the extent of WGS reaction is shown in Figures $5 \mathrm{a}$ and $5 \mathrm{~b}$. The usage ratio decreases whereas the $\mathrm{CO}_{2}$ selectivity increases with an increase in conversion (at constant temperature) or with an increase in temperature (at constant conversion of the limiting reactant). This trend is the same regardless of feed composition $\left(\mathrm{H}_{2} / \mathrm{CO}=0.67\right.$ in Fig. $5 a$, or $\mathrm{H}_{2} / \mathrm{CO}=2$ in Fig. $\left.5 b\right)$. From the stoichiometry it is expected that the extent of WGS reaction (secondary or consecutive reaction) will increase with increase in conversion, which is manifested in a decrease of the usage ratio and increase in $\mathrm{CO}_{2}$ selectivity. The increase in WGS activity (higher $\mathrm{CO}_{2}$ selectivity and lower UR) with increase in temperature (at constant conversion) is a kinetic effect. Reaction pressure has the opposite effect, i.e. the extent of the WGS reaction increases (lower UR and higher $\mathrm{CO}_{2}$ selectivity) with decrease in total pressure (data not shown).

Changes in the usage ratio result in changes in the exit (i.e. reactor) $\mathrm{H}_{2} / \mathrm{CO}$ ratio as shown in Figure 6. These data were obtained under different process conditions ( $\mathrm{T}, \mathrm{P}$ and space 
velocity) but all data are well represented by the two curves, one for each of the two $\mathrm{H}_{2} / \mathrm{CO}$ feed ratios. As the extent of WGS reaction increases (i.e. UR decreases) the reactor $\mathrm{H}_{2} / \mathrm{CO}$ ratio increases dramatically for $\mathrm{H}_{2} / \mathrm{CO}=2$ feed gas, and only slightly for $\mathrm{H}_{2} / \mathrm{CO}=0.67$ feed gas. This in turn has a significant effect on FTS selectivity as shown in the next section.

\subsection{Effect of $\mathrm{H}_{2} / \mathrm{CO}$ ratio on FTS selectivity}

For the inlet $\mathrm{H}_{2} / \mathrm{CO}$ ratio of 0.67 , the limiting reactant is hydrogen, while in the case of $\mathrm{H}_{2} / \mathrm{CO}=2$ the limiting reactant is carbon monoxide. The $\mathrm{H}_{2} / \mathrm{CO}$ ratio inside the reactor corresponds to the ratio at the outlet. In this part we will only compare the effect on selectivity of low vs. high $\mathrm{H}_{2} / \mathrm{CO}$ ratio, which remain far enough apart regardless whether we are looking at inlet or outlet reactant ratios.

Our data shows that the increase in $\mathrm{H}_{2} / \mathrm{CO}$ feed ratio results in higher selectivity of light products $\left(\mathrm{CH}_{4}\right.$ and $\left.\mathrm{C}_{2}-\mathrm{C}_{4}\right)$ whereas $\mathrm{C}_{5+}$ selectivity decreases (Figure $\left.7 \mathrm{a}\right)$. These trends are typically observed with all FTS catalysts [8, 13,14-16, 34]. This is related to the decrease of chain growth probability with increasing $\mathrm{H}_{2} / \mathrm{CO}$ ratio both at the inlet and inside the reactor (Figure 7b). Donnelly and Satterfield [15] conducted studies with unpromoted Fe and Ruhrchemie catalysts in a slurry reactor and reported that chain growth probabilities $\alpha_{1}$ and $\alpha_{2}$ (based on so called double alpha model [54]) depend very little on $\mathrm{H}_{2} / \mathrm{CO}$ ratio in the reactor (range of 0.3-3). However, the data shown for unpromoted Fe have a great deal of variation for a given value of $\mathrm{H}_{2} / \mathrm{CO}$ ratio, whereas no data have been presented for the Ruhrchemie catalyst. Dictor and Bell [16] conducted studies with unpromoted and potassium promoted Fe catalysts in a slurry reactor under differential conditions (CO conversion less than 5\%). They found that $\alpha$

(for $\mathrm{C}_{1}-\mathrm{C}_{7}$ hydrocarbons) decreases with increasing $\mathrm{H}_{2} / \mathrm{CO}$ ratio on both catalysts (the magnitude of change being smaller for $\mathrm{K}$ promoted catalyst). Liu et al. [17] conducted studies with 
potassium promoted $\mathrm{Fe} / \mathrm{Mn}$ catalyst in a spinning basket reactor, and their results show that increase in $\mathrm{H}_{2} / \mathrm{CO}$ ratio leads to preferential chain termination manifested in increase of $\mathrm{CH}_{4}$ and light hydrocarbons, and lower content of high molecular weight products (ASF plots). A logical interpretation for these observations is that the increase in $\mathrm{H}_{2} / \mathrm{CO}$ causes an increase in $\mathrm{H}$ surface coverage in relation to monomer coverage resulting in an increased rate of chain termination.

Our results show that OPR decreases significantly and selectivity towards 2-olefins increases with increasing $\mathrm{H}_{2} / \mathrm{CO}$ ratio (Figure 7c) which is in agreement with previous results obtained in our laboratory with the same catalyst [14, 35]. Donnelly and Satterfield [14] reported decrease in OPR, and increase in 2-olefin content for $\mathrm{C}_{4}$ hydrocarbons only, with increase in the reactor $\mathrm{H}_{2} / \mathrm{CO}$ ratio. Dictor and Bell [16] reported that the percentage of olefins decreases with an increase in partial pressure of $\mathrm{H}_{2}$ (at constant partial pressure of $\mathrm{CO}$ ) for $\mathrm{K}$ promoted $\mathrm{Fe}$ catalyst, but did not present any data for 2-olefin selectivity due to the small amounts of products produced under differential conditions. Liu et al. [17] reported increase in hydrogenation (less olefins in $\mathrm{C}_{2}-\mathrm{C}_{4}$ carbon number range) with increase in $\mathrm{H}_{2} / \mathrm{CO}$ feed ratio. The decrease in 1olefins is caused by increases in both primary and secondary hydrogenation reactivity. An effect that could have influence on the decrease of OPR with increasing $\mathrm{H}_{2} / \mathrm{CO}$ is the reduction in CO partial pressure, due to inhibiting properties of $\mathrm{CO}$ to secondary hydrogenation. For the conditions shown in Figure 7 the $\mathrm{CO}$ conversion was kept constant with increasing $\mathrm{H}_{2} / \mathrm{CO}$, which meant SV was increased simultaneously. Lower residence time at high $\mathrm{H}_{2} / \mathrm{CO}$ condition would have decreased the secondary reactivity of 1-olefins, i.e. increased OPR. However since OPR decreased it is evident that increasing $\mathrm{H}_{2} / \mathrm{CO}$ had a more significant effect compared to the residence time.

\subsection{Effect of temperature on FTS selectivity}


The effect of temperature for Fe catalyzed FTS reaction has been reported many times in the literature. The consensus is that with increasing temperature the amount of light products increases while that of heavy products decreases [13-15,19, 35, 36], which is linked to decrease in chain growth probability. However, this effect is much more pronounced with cobalt and ruthenium than with iron FTS catalysts [2, 37]. On the other hand, the increase of T is sometimes reported to increase olefin content $[15,16,38]$, however the opposite trend was observed as well $[15,39,40]$. Our data show that $\alpha_{\mathrm{n}}$ typically slowly decreased with increase in $\mathrm{T}$ (Figure 8b), for a given pressure and reactant feed ratio (noting that the reactant ratio inside the reactor is relatively constant). This explains trends shown in Figure 8a, where methane and $\mathrm{C}_{2}-\mathrm{C}_{4}$ selectivities increase, whereas $\mathrm{C}_{5+}$ selectivity decreases with increasing $\mathrm{T}$.

The growth probability is kinetically determined by the ratio between rates of chain propagation $\left(R_{p, n}\right)$ and termination reactions $\left(R_{t, n}\right)$ :

$$
\alpha_{n}=\frac{R_{p, n}}{R_{p, n}+R_{t, n}}
$$

The rates of these surface reactions are determined by corresponding rate constants and surface coverages of monomeric species and atomic hydrogen, which all vary with changing temperature. The main effect of temperature would be to change rate constants of FTS chain propagation and termination that determine $\alpha_{\mathrm{n}}$ (Eq. 15). The reaction with higher activation energy will respond faster to changes in T. The implication of decreasing $\alpha_{n}$ with $T$ is that the chain termination has a higher activation energy than the chain propagation. However, relatively slow decrease of $\alpha_{n}$ with temperature (within the tested range 493-533 K) suggests that the difference between the two activation energies is relatively small. 
Our data showed mixed results for OPR variation with changing $\mathrm{T}$, which is consistent with literature studies $[15,16,38,39]$. The analysis of $T$ effect on OPR is difficult because of a number of temperature related processes that would affect OPR. The effects that could, along with others, cause a change of OPR with increasing $\mathrm{T}$ are:

1) Higher activation energy of chain hydrogenation (n-paraffin formation) compared to desorption (1-olefin formation) [41-43] would cause a decrease of OPR with increased $\mathrm{T}$.

2) Increased FTS reaction rate with $T$ causes increase in partial pressure of water, which inhibits secondary olefin reactions, leading to higher OPR [44, 45].

It should also be pointed out that residence time in our study decreased with increasing $\mathrm{T}$, which would favor the increase of OPR due to lower extent of secondary olefin reactions. Also interesting is that even though the OPR remained relatively constant with temperature, the amount of 2-olefins increased (Figure 8c). The same qualitative trend with respect to 2-olefin selectivity was reported in other studies with Ruhrchemie catalyst $[14,15]$. This could mean that the activation energy for 2-olefin formation is higher compared to those for 1-olefin and nparaffin formation.

\subsection{Effect of pressure on FTS selectivity}

It is well known that total pressure has a positive effect on FTS reaction rate [13, 17, 39, 46]. A positive effect has also been reported on FTS product selectivity, decreasing methane and increasing $\mathrm{C}_{5+}$, for cobalt-based catalysts $[33,46]$. For iron catalysts the same effect has been reported [47], but the influence of total pressure on selectivity for this catalyst is much smaller than for cobalt [48]. Botes et al. [2] studied the effect of syngas pressure on methane selectivity at constant outlet $\mathrm{H}_{2} / \mathrm{CO}$ of 2 showing no variations of methane selectivity between 4 and 25 bar. 
Similar trend, negligible effect of pressure on FTS selectivity over Fe catalysts, was reported by Dry [13].

Figure 9 shows the detailed product distribution features as a function of total pressure at 1.5 and 2.5 MPa (temperature and inlet feed ratio are kept constant and conversion values are similar). Selectivity towards light products (methane and $\mathrm{C}_{2}-\mathrm{C}_{4}$ ) decreased and $\mathrm{C}_{5+}$ selectivity increased with total pressure (Figure 9a). These changes can be related to variations in $\alpha_{\mathrm{n}}$ (Figure 9b), which shows slight increase with increasing total pressure. The reason for this behavior can be explained in terms of kinetics as a decrease of hydrogen to carbon monoxide coverage ratio. Dinse et al. [46] showed that the decrease of hydrogen to carbon monoxide coverage ratio favors propagation over chain termination via hydrogenation, therefore causing increase in $\alpha_{n}$.

We would like to point out that for conditions in our experiments the outlet $\mathrm{H}_{2} / \mathrm{CO}$ ratio was not constant at different total pressure; it decreased with increasing P. This would also cause a decrease of $\mathrm{H} / \mathrm{CO}$ surface coverage ratio and the observed product selectivity variations. Therefore, it can be expected that at a constant outlet $\mathrm{H}_{2} / \mathrm{CO}$ ratio the effect of changing $\mathrm{P}$ on selectivity would have been much lower, as reported by Botes [2].

OPR increases with increasing P (Figure 9c), which can be caused by several processes:

1) Decrease in primary n-paraffin formation by chain hydrogenation due lower outlet $\mathrm{H}_{2} / \mathrm{CO}$ ratio.

2) Decrease in secondary 1-olefin reactions due to lower outlet (and surface) $\mathrm{H}_{2} / \mathrm{CO}$ ratio, because $\mathrm{H}_{2}$ promotes secondary hydrogenation and $\mathrm{CO}$ suppresses secondary reactions altogether [49].

3) Higher water partial pressure due to higher total pressure suppresses secondary reactions of 1-olefins [45]. 
Increased partial pressure of in-situ formed 1-olefins would have increased rate of their secondary reactions, however this effect seems to be minor in comparison to factors that suppress secondary reactions and increase OPR. The 2-olefin content, i.e. 2-olefin/total olefin ratio, decreased with increasing total pressure (see Figure 9c). Dictor and Bell [16] and Egiebor et al. $[50,51]$ reported that internal olefins are formed through secondary reactions of 1-olefins over iron-based catalysts. This explanation would be consistent with our results, since 2-olefins content is decreasing, while OPR is increasing, with increasing pressure.

\subsection{Effect of conversion level on FTS selectivity}

Conversion level at fixed values of temperature, pressure and feed ratio was controlled by varying the space velocity (SV) in 0.5 to $23.5 \mathrm{NL} /\left(\mathrm{g}_{\text {cat }} * \mathrm{~h}\right)$ range. CO conversions from 9 to $84 \%$ were achieved. For the majority of data varying space velocity did not have a significant effect on hydrocarbon product selectivity (Figures $10 \mathrm{a}$ and $10 \mathrm{~b}$ ), i.e. typically $\mathrm{CH}_{4}$ and $\mathrm{C}_{5+}$ selectivity remains relatively constant at different conversions (i.e. residence time). Bukur et al. [14] reported the same result. This is consistent with relatively constant values of chain growth probabilities at different conversions (Figure 11a), which was also found in other studies with potassium promoted Fe catalysts $[15,16]$. OPR decreases with increase in residence time (Figure 11b) due to 1-olefin secondary reactions (hydrogenation, isomerization and readsorption). Very small changes in OPR with increase in SV were reported by Donnelly and Satterfield [15] and Dictor and Bell [16]. From Figure 11b we see that the amount of 2-olefins in the products increases with increased residence time, which would be expected if 2-olefins are formed by isomerization of 1-olefins.

\subsection{Oxygenate formation}


In addition to hydrocarbons, products containing oxygen atoms (mainly alcohols) are formed as well. Oxygenates are a minor product of FTS and their content can vary depending on the process conditions $[8,13]$.

Figure 12a shows the molar flowrates of different chain length oxygenates together with flowrates of hydrocarbon products. It is clear that oxygenates are minor products compared to nparaffin and 1-olefin. However, some studies suggest that oxygenates cannot be neglected when analyzing the product distribution of low weight molecules, mainly $\mathrm{C}_{1}$ and $\mathrm{C}_{2}$, since neglecting them could lead to more significant deviations from ASF [52]. This can be seen, to some extent, in our results as well (Figure 12b), where inclusion of oxygenates leads to smaller deviations from ASF distribution (notably $\mathrm{C}_{1}$ and $\mathrm{C}_{2}$ products) compared to hydrocarbons only. However, overall non-ASF behavior (different slope for $\mathrm{C}_{10+}$ products) is unaffected by the inclusion of oxygenate products into the product distribution plot. It is also interesting to note that oxygenates and olefins have a different slope compared to n-paraffin in the range above $\mathrm{C}_{9}$ (Figure 12a). This refers to the so-called "break in the ASF" or non-ASF behavior. Wojciechowski [53] interpreted this as proof that n-paraffins have two different termination steps, one with addition of hydrogen atoms and one with the addition of methyl group to the growing chain, while olefin and oxygenates only have one. Huff and Saterfield [54] hypothesized that some molecules (including oxygenates, olefins and lighter paraffins) are created on a separate type of active sites, compared to the heavier paraffins. Additional explanations for these differences in slopes with carbon number are the existence of secondary reactions of 1-olefin and oxygenates [10, 55], as well as the dependence of 1-olefin desorption rates on chain length [56-58]. It should be noted, though, that the latter theory was only applied to 1-olefins and not to oxygenates. 
The oxygenate products formed in FTS are mainly low molecular weight oxygenates and the amount of formed oxygenates quickly declines with carbon number. The oxygenate slope in the ASF plot is steeper compared to n-paraffin and 2-olefin, and is similar to that of 1-olefins (see Figure 12a). This could suggest some similarities in the formation of oxygenates and 1olefins in FTS [59]. Both species are well-known to participate in secondary reactions. Tau et al. cofeeding study [55], as well as other studies (see Ref. [60] and therein), showed that externally added n-alcohols undergo hydrogenolysis to corresponding n-paraffin, dehydrogenation to aldehyde or ketone, as well as reincorporation and continued chain growth to hydrocarbons. The chain-length dependency of n-alcohol secondary reactions is likely the reason for the lack of higher molecular weight oxygenate products. Our results show that oxygenate flowrates decrease with increasing residence time (Figure 13), which is an indirect proof of oxygenate secondary reactivity. This is consistent with results obtained at Sasol with Fe catalysts [13].

The oxygenate content can be calculated in relation to hydrocarbons as:

$$
\text { Oxygenates }(w t . \%)=100 \% \times \frac{\dot{m}_{\text {Oxygenates }}}{\dot{m}_{\text {Oxygenates }}+\dot{m}_{H C, \text { total }}}
$$

where $\dot{m}_{\text {Oxygenates }}$ and $\dot{m}_{H C, \text { total }}$ are mass flowrates of oxygenates and hydrocarbons, respectively.

The effect of process conditions on oxygenate formation is rarely reported in the literature due to the difficulty to analyze relatively low amounts of these products. Our results show decrease in oxygenate content with increasing temperature and an increase with increasing reactant feed ratio (Figure 14) which is consistent with [13]. An increase in oxygenates content was reported for higher pressures $[8,13]$, however our results showed complex behavior for pressure variations. This could be related to variations of partial pressures with the changing extent of WGS. 


\section{Conclusions}

Variations in FTS hydrocarbon selectivity, as a result of changes in process conditions, are related to changes in chain growth probabilities. Studying these probabilities can lead to better understanding of intrinsic kinetics of FTS surface reactions. In this study we showed that increasing temperature and $\mathrm{H}_{2} / \mathrm{CO}$ feed ratio decreases the growth probabilities, leading to increased methane and lower $\mathrm{C}_{5+}$ selectivity. Pressure increase was shown to have a positive, albeit slight, effect on selectivity. The conversion effect on selectivity is complex and selectivity towards methane and $\mathrm{C}_{5^{+}}$does not seem to be significantly affected by variations in residence time. Considering all of the conditions tested we can conclude that values of $C_{1}$ and $C_{2}$ growth probabilities are close to those of $\mathrm{C}_{3+}$ species and do not exhibit significantly different behavior at different process conditions. Unlike for cobalt-based FTS catalysts where $\mathrm{C}_{1}$ is the dominant cause for selectivity changes [34], with iron catalyst all of the growth probabilities seem to change in parallel and contribute to selectivity shifts.

Process conditions determine the content of different hydrocarbon species, primarily nparaffin, 1- and 2-olefin, as well as oxygenate formation. As seen from variations of 1-olefin/nparaffin ratio, increasing residence time and $\mathrm{H}_{2} / \mathrm{CO}$ ratio favored secondary 1-olefin reactivity and resulted in a lower OPR. The effect of pressure and temperature on 1-olefin content was shown to be smaller and more complex. 2-olefin content in olefins increases with increasing residence time, temperature and $\mathrm{H}_{2} / \mathrm{CO}$ ratio, while pressure increase has the opposite effect. Oxygenate formation was most affected by temperature and $\mathrm{H}_{2} / \mathrm{CO}$ ratio variations. Decrease of oxygenate content at higher residence time is related to their participation in secondary reactions. 


\section{Acknowledgements}

We acknowledge the financial support from US DOE (Grant No. DE-FG26-02NT41540) for experimental work presented in this paper. B.T. and D.B.B. acknowledge the support from Qatar

Foundation. N.M.N. acknowledges the financial support from Ministry of Education, Science and Technological Development of the Republic of Serbia (Project No. 172022). 


\section{References}

[1] F. Fischer and H. Tropsch, Brennstoff Chem, 7 (1926) 97.

[2] F.G. Botes, J.W. Niemantsverdriet and J. van de Loosdrecht, Catalysis Today, 215 (2013)

112.

[3] B.H. Davis, Industrial \& Engineering Chemistry Research, 46 (2007) 8938.

[4] B.H. Davis, Fuel Process. Technol., 71 (2001) 157.

[5] R.A. van Santen, I.M. Ciobîcă, E. van Steen and M.M. Ghouri, in C.G. Bruce and K. Helmut (Editors), Advances in Catalysis, Vol. Volume 54, Academic Press, 2011, p. 127.

[6] R.B. Anderson, R.A. Friedel and H.H. Storch, J. Chem. Phys., 19 (1951) 313.

[7] G.P. van der Laan and A.A.C.M. Beenackers, Industrial \& Engineering Chemistry Research, 38 (1999) 1277.

[8] G.P. van der Laan and A.A.C.M. Beenackers, Catalysis reviews. Science and engineering, 41 (1999).

[9] C.H. Bartholomew and R.J. Farrauto, Fundamentals of Industrial Catalytic Processes, John Wiley \& Sons, 2006.

[10] L.M. Tau, H.A. Dabbagh and B.H. Davis, Energy \& Fuels, 4 (1990) 94.

[11] M.K. Gnanamani, R.A. Keogh, W.D. Shafer and B.H. Davis, Applied Catalysis A: General, 393 (2011) 130.

[12] S.L. Soled, E. Iglesia, S. Miseo, B.A. DeRites and R.A. Fiato, Top. Catal., 2 (1995) 193.

[13] M.E. Dry, in A.P. Steynberg and M.E. Dry (Editors), Studies in Surface Science and Catalysis, Vol. Volume 152, Elsevier, 2004, p. 196.

[14] D.B. Bukur, S.A. Patel and X. Lang, Appl. Catal., 61 (1990) 329.

[15] T.J. Donnelly and C.N. Satterfield, Appl. Catal., 52 (1989) 93.

[16] R.A. Dictor and A.T. Bell, Journal of Catalysis, 97 (1986) 121.

[17] Y. Liu, B.-T. Teng, X.-H. Guo, Y. Li, J. Chang, L. Tian, X. Hao, Y. Wang, H.-W. Xiang, Y.-Y. Xu and Y.-W. Li, J. Mol. Catal. A: Chem., 272 (2007) 182.

[18] S. Ozkara-Aydinoglu, O. Atac, O.F. Gul, S. Kinayyigit, S. Sal, M. Baranak and I. Boz, Chem. Eng. J. (Amsterdam, Neth.), 181-182 (2012) 581.

[19] M.E. Dry, in J.R. Anderson and M. Boudart (Eds.), Catalysis Science and Technology, Vol. 1, Springer, 1981, p. 159.

[20] H. Arakawa and A.T. Bell, Ind. Eng. Chem. Process Des. Dev., 22 (1983) 97.

[21] D.B. Bukur, D. Mukesh and S.A. Patel, Industrial \& Engineering Chemistry Research, 29 (1990) 194.

[22] C.H. Bartholomew, R.B. Pannell and J.L. Butler, Journal of Catalysis, 65 (1980) 335.

[23] R.C. Reuel and C.H. Bartholomew, Journal of Catalysis, 85 (1984) 63.

[24] R.C. Reuel and C.H. Bartholomew, Journal of Catalysis, 85 (1984) 78.

[25] C.H. Bartholomew and R.C. Reuel, Industrial and Engineering Chemistry Product Research and Development, 24 (1985) 56.

[26] M. Rameswaran and C.H. Bartholomew, Journal of Catalysis, 117 (1989) 218.

[27] C.D. Frohning, W. Rotting and F. Schnur, Chemierohstoffe aus kohle, Thieme, Stuttgart, 1977.

[28] W.H. Zimmerman and D.B. Bukur, The Canadian Journal of Chemical Engineering, 68 (1990) 292.

[29] M.E. Dry, Applied Catalysis A: General, 138 (1996) 319. 
[30] W. Ma, Y. Ding, V.H. Carreto Vazquez and D.B. Bukur, Applied Catalysis A:Genreral, 268 (2004) 99.

[31] D.B. Bukur, L. Nowicki, R.K. Manne and X. Lang, Journal of Catalysis, 155 (1995) 366.

[32] D.B. Bukur, L. Nowicki and S. Patel, Canadian Journal of Chemical Engineering, 74 (1996) 399.

[33] M.J. van Vuuren, J. Huyser, T. Grobler and G. Kupi, Chem. Ind. (Boca Raton, FL, U. S.), 128 (2010) 229.

[34] B. Todic, W. Ma, G. Jacobs, B.H. Davis and D.B. Bukur, Journal of Catalysis, 311 (2014)

325.

[35] D.B. Bukur, X. Lang, A. Akgerman and Z. Feng, Ind. Eng. Chem. Res., 36 (1997) 2580.

[36] M.E. Dry, J. Mol. Catal., 17 (1982) 133.

[37] J. Yang, W. Ma, D. Chen, A. Holmen and B.H. Davis, Applied Catalysis A: General, 470 (2014) 250.

[38] R.B. Anderson, in P.H. Emmett (Ed.), Catalysis, Vol. 4,Van Nostrand-Reinhold, New York (1956).

[39] M. Claeys and E. van Steen, Stud. Surf. Sci. Catal., 152 (2004) 601.

[40] H. Schulz and H. Gokcebay, Catalysis of Organic Reactions, Marcel Dekker, New York, 1984.

[41] J. Yang, Y. Liu, J. Chang, Y.-N. Wang, L. Bai, Y.-Y. Xu, H.-W. Xiang, Y.-W. Li and B. Zhong, Industrial \& Engineering Chemistry Research, 42 (2003) 5066.

[42] B. Teng, J. Chang, H. Wan, J. Lu, S. Zheng, Y. Liu, Y. Liu and X. Guo, Chinese Journal of Catalysis, 28 (2007) 687.

[43] G. Lozano-Blanco, J.W. Thybaut, K. Surla, P. Galtier and G.B. Marin, Industrial \& Engineering Chemistry Research, 47 (2008) 5879.

[44] J.H. Boelee, J.M.G. Cuesters and K. Van der Wiele, Appl. Catal., 53 (1989) 1.

[45] A.K. Dalai and B.H. Davis, Applied Catalysis A: General, 348 (2008) 1.

[46] A. Dinse, M. Aigner, M. Ulbrich, G.R. Johnson and A.T. Bell, Journal of Catalysis, 288 (2012) 104.

[47] A. Rafiee and M. Hillestad, Chem. Eng. Technol., 36 (2013) 1729.

[48] F.G. Botes, J.W. Niemantsverdriet and J. van de Loosdrecht, Catalysis Today.

[49] H. Schulz and M. Claeys, Applied Catalysis A: General, 186 (1999) 71.

[50] N.O. Egiebor and W.C. Cooper, Appl. Catal., 14 (1985) 323.

[51] N.O. Egiebor, W.C. Cooper and B.W. Wojciechowski, Can. J. Chem. Eng., 63 (1985)

826.

[52] C.N. Satterfield and G.A. Huff, Jr., Journal of Catalysis, 73 (1982) 187.

[53] B.W. Wojciechowski, Can. J. Chem. Eng., 64 (1986) 149.

[54] G.A. Huff, Jr. and C.N. Satterfield, Journal of Catalysis, 85 (1984) 370.

[55] L.M. Tau, H.A. Dabbagh, J. Halasz and B.H. Davis, J. Mol. Catal., 71 (1992) 37.

[56] F.G. Botes, Energy \& Fuels, 21 (2007) 1379.

[57] B. Todic, T. Bhatelia, G.F. Froment, W. Ma, G. Jacobs, B.H. Davis and D.B. Bukur, Industrial \& Engineering Chemistry Research, 52 (2013) 669.

[58] B. Todic, W. Ma, G. Jacobs, B.H. Davis and D.B. Bukur, Catalysis Today, 228 (2014) 32.

[59] D. Chakrabarti, M.K. Gnanamani, W.D. Shafer, M.C. Ribeiro, D.E. Sparks, V. Prasad, A. de Klerk and B.H. Davis, Industrial \& Engineering Chemistry Research, 54 (2015) 6438. 
[60] J. Gaube and H.F. Klein, Journal of Molecular Catalysis A: Chemical, 283 (2008) 60. 


\section{List of Tables:}

Table 1 - Reaction conditions and selectivity results.

\section{List of Figures:}

Figure 1 - Schematic of stirred tank slurry reactor.

Figure 2 - Effect of time at the baseline conditions (initial period) and reproducibility of results from three tests: (a) $\mathrm{CO}$ conversion, (b) Methane and $\mathrm{C}_{5}{ }^{+}$selectivity. (Process conditions: $\mathrm{T}=$ $\left.513 \mathrm{~K}, \mathrm{P}=1.5 \mathrm{MPa}, \mathrm{H}_{2} / \mathrm{CO}=2, \mathrm{SV}=4.0 \mathrm{NL} /\left(\mathrm{g}_{\mathrm{Fe}}{ }^{* h}\right)\right)$.

Figure 3 - Effect of time on activity and selectivity: (a) CO conversion, (b) Methane and $\mathrm{C}_{5}^{+}$ selectivity. (Process conditions: $\mathrm{T}=513 \mathrm{~K}, \mathrm{P}=1.5 \mathrm{MPa}, \mathrm{H}_{2} / \mathrm{CO}=2, \mathrm{SV}=4.0 \mathrm{NL} /\left(\mathrm{g}_{\mathrm{Fe}}{ }^{*} \mathrm{~h}\right)$ ).

Figure 4 - Effect of time on hydrocarbon product distribution: (a) mole fractions of total hydrocarbon; (b) 1-olefin/n-paraffin ratio with carbon number. (Process conditions: T = $513 \mathrm{~K}, \mathrm{P}$ $\left.=1.5 \mathrm{MPa}, \mathrm{H}_{2} / \mathrm{CO}=2, \mathrm{SV}=4.0 \mathrm{NL} /\left(\mathrm{g}_{\mathrm{Fe}} * \mathrm{~h}\right)\right)$.

Figure 5 - The effect of process conditions on UR and $\mathrm{CO}_{2}$ selectivity: a) effect of $\mathrm{T}$ at low $\mathrm{H}_{2} / \mathrm{CO}$ feed ratio; b) effect of $\mathrm{T}$ at high $\mathrm{H}_{2} / \mathrm{CO}$ feed ratio.

Figure 6 - Variation of outlet $\mathrm{H}_{2} / \mathrm{CO}$ ratio with UR for inlet $\mathrm{H}_{2} / \mathrm{CO}$ ratios of 0.67 and 2. (Note: temperature, pressure and space velocity are varied).

Figure 7 - Effect of inlet $\mathrm{H}_{2} / \mathrm{CO}$ ratio on: (a) selectivity of $\mathrm{CH}_{4}, \mathrm{C}_{2}-\mathrm{C}_{4}$ and $\mathrm{C}_{5+}$; (b) chain growth probability with carbon; (c) 1-olefin-to-n-paraffin ratio and 2-olefin content with carbon number. (Process conditions: $\mathrm{T}=513 \mathrm{~K}, \mathrm{P}=1.5 \mathrm{MPa}, \mathrm{X}_{\mathrm{CO}}=55-56 \%$, outlet $\mathrm{H}_{2} / \mathrm{CO}$ ratio $=0.58$ and 2.92). 
Figure 8 - Effect of temperature on: (a) selectivity of $\mathrm{CH}_{4}, \mathrm{C}_{2}-\mathrm{C}_{4}$ and $\mathrm{C}_{5+}$; (b) chain growth probability with carbon number; (c) 1-olefin-to-n-paraffin ratio and 2-olefin content with carbon number. (Process conditions: $\mathrm{P}=1.5 \mathrm{MPa}$, inlet $\mathrm{H}_{2} / \mathrm{CO}=0.67$, outlet $\mathrm{H}_{2} / \mathrm{CO}=0.50-0.58, \mathrm{X}_{\mathrm{CO}}$ $=27-46 \%)$.

Figure 9 - Effect of pressure on: (a) selectivity of $\mathrm{CH}_{4}, \mathrm{C}_{2}-\mathrm{C}_{4}$ and $\mathrm{C}_{5+}$; (b) chain growth probability with carbon number; (c) 1-olefin-to-n-paraffin ratio and 2-olefin content with carbon number; (Process conditions: $\mathrm{T}=533 \mathrm{~K}$, inlet $\mathrm{H}_{2} / \mathrm{CO}=0.67$, outlet $\mathrm{H}_{2} / \mathrm{CO}=0.48-0.56, \mathrm{X}_{\mathrm{CO}}=$ $36-46 \%)$.

Figure 10 - Variation of $\mathrm{CH}_{4}$ and $\mathrm{C}_{5+}$ product selectivity with $\mathrm{CO}$ conversion level for selected conditions: a) data at inlet $\mathrm{H}_{2} / \mathrm{CO}=0.67$ and different $\mathrm{T}$ and $\mathrm{P}$; b) data at inlet $\mathrm{H}_{2} / \mathrm{CO}=2.0$ and different $\mathrm{T}$ and $\mathrm{P}$; (Note: Lines connect points with same $\mathrm{T}$, $\mathrm{P}$ and inlet $\mathrm{H}_{2} / \mathrm{CO}$ ).

Figure 11 - Variation of main product formation features with carbon number and residence time: a) chain growth probability with carbon number; b) 1-olefin to n-paraffin ratio and 2-olefin to total olefin ratio with carbon number $\left(\mathrm{T}=533 \mathrm{~K}, \mathrm{P}=2.5 \mathrm{MPa}\right.$, inlet $\mathrm{H}_{2} / \mathrm{CO}=0.67$ and outlet $\mathrm{H}_{2} / \mathrm{CO}$ ratio $\left.=0.53-0.54\right)$.

Figure 12 - Oxygenates as minor products in FTS: a) Molar flowrates of different FTS product species; b) Hydrocarbon and total product molar flowrates. (Process conditions: $\mathrm{T}=513 \mathrm{~K}, \mathrm{P}=$ $\left.1.5 \mathrm{MPa}, \mathrm{H}_{2} / \mathrm{CO}=2, \mathrm{X}_{\mathrm{CO}}=55 \%\right)$.

Figure 13 - Effect of residence time on the oxygenate formation. (Process conditions: $\mathrm{T}=533$ $\mathrm{K}, \mathrm{P}=1.5 \mathrm{MPa}$, inlet $\mathrm{H}_{2} / \mathrm{CO}=0.67$, outlet $\mathrm{H}_{2} / \mathrm{CO}$ ratio $=0.56$ and 0.84 ).

Figure 14 - Effect of process conditions on the oxygenate selectivity: a) Effect of temperature; b) Effect of inlet $\mathrm{H}_{2} / \mathrm{CO}$ ratio. 
Table 1

\begin{tabular}{|c|c|c|c|c|c|c|c|c|c|c|c|c|c|c|c|c|c|c|c|}
\hline \multirow{3}{*}{ Run } & \multirow{3}{*}{ No. } & \multirow{3}{*}{$\begin{array}{c}\text { TOS } \\
\mathrm{h}\end{array}$} & \multirow{3}{*}{$\begin{array}{l}\mathbf{T} \\
\mathrm{K}\end{array}$} & \multirow{3}{*}{$\begin{array}{c}\mathrm{P} \\
\mathrm{MPa}\end{array}$} & \multirow{3}{*}{$\begin{array}{c}\text { Inlet } \\
\mathrm{H}_{2} / \mathrm{CO}\end{array}$} & \multirow{3}{*}{$\begin{array}{l}\text { Outlet } \\
\mathrm{H}_{2} / \mathrm{CO}\end{array}$} & \multirow{3}{*}{$\begin{array}{c}\mathrm{SV} \\
\mathrm{NL} / \mathrm{g}- \\
\mathrm{Fe} / \mathrm{h}\end{array}$} & \multirow{3}{*}{$\begin{array}{c}\mathbf{X}_{\mathrm{CO}} \\
\%\end{array}$} & \multirow{3}{*}{$\begin{array}{c}\mathrm{X}_{\mathrm{H} 2} \\
\%\end{array}$} & \multirow{3}{*}{$\begin{array}{c}\mathrm{X}_{\mathrm{CO}+\mathrm{H} 2} \\
\%\end{array}$} & \multirow{3}{*}{$\begin{array}{c}\text { UR } \\
- \\
\end{array}$} & \multirow{3}{*}{$\begin{array}{c}\mathbf{P}_{\mathrm{co}} \\
\mathrm{MPa}\end{array}$} & \multirow{3}{*}{$\begin{array}{l}\mathbf{P}_{\mathrm{H} 2} \\
\mathrm{MPa}\end{array}$} & \multirow{3}{*}{$\begin{array}{l}\mathbf{P}_{\mathrm{H} 2 \mathrm{O}} \\
\mathrm{MPa}\end{array}$} & \multirow{3}{*}{$\begin{array}{l}\mathrm{P}_{\mathrm{CO} 2} \\
\mathrm{MPa}\end{array}$} & \multicolumn{4}{|c|}{ Selectivity } \\
\hline & & & & & & & & & & & & & & & & $\mathrm{CH}_{4}$ & $C_{2}-C_{4}$ & $C_{5+}$ & \multirow{2}{*}{$\begin{array}{c}\mathrm{CO}_{2} \\
\mathrm{~mol} . \%\end{array}$} \\
\hline & & & & & & & & & & & & & & & & & -atom & & \\
\hline \multirow{12}{*}{1} & $1^{b}$ & 78 & 533 & 1.50 & 0.67 & 0.58 & 4.0 & 54 & 60 & 57 & 0.74 & 0.63 & 0.37 & 0.08 & 0.33 & 4.0 & 19.4 & 76.6 & 43.2 \\
\hline & 2 & 101 & 533 & 1.50 & 0.67 & 0.84 & 1.7 & 84 & 80 & 82 & 0.64 & 0.31 & 0.26 & 0.06 & 0.71 & 3.0 & 12.4 & 51.3 & 29.8 \\
\hline & 3 & 126 & 533 & 1.50 & 0.67 & 0.56 & 9.2 & 27 & 39 & 31 & 0.98 & 0.82 & 0.46 & 0.06 & 0.11 & 3.8 & 19.4 & 76.8 & 32.8 \\
\hline & 4 & 164 & 513 & 1.50 & 0.67 & 0.54 & 2.0 & 39 & 51 & 45 & 0.88 & 0.76 & 0.41 & 0.09 & 0.18 & 2.7 & 13.5 & 83.8 & 32.1 \\
\hline & 5 & 215 & 513 & 1.50 & 0.67 & 0.58 & 1.0 & 56 & 62 & 59 & 0.74 & 0.62 & 0.36 & 0.07 & 0.36 & 3.3 & 18.7 & 77.9 & 40.0 \\
\hline & 6 & 238 & 513 & 1.50 & 0.67 & 0.58 & 5.5 & 14 & 25 & 18 & 1.22 & 0.87 & 0.50 & 0.05 & 0.04 & 3.0 & 15.5 & 81.5 & 20.2 \\
\hline & $7^{b}$ & 270 & 533 & 1.50 & 0.67 & 0.56 & 4.0 & 46 & 54 & 50 & 0.79 & 0.69 & 0.39 & 0.08 & 0.26 & 4.3 & 20.7 & 75.0 & 41.3 \\
\hline & 8 & 310 & 513 & 1.50 & 2.00 & 2.63 & 4.2 & 46 & 29 & 36 & 1.26 & 0.34 & 0.89 & 0.11 & 0.08 & 7.2 & 23.6 & 69.2 & 24.9 \\
\hline & 9 & 338 & 513 & 1.50 & 2.00 & 2.18 & 10.8 & 22 & 15 & 18 & 1.35 & 0.43 & 0.93 & 0.06 & 0.02 & 2.9 & 16.0 & 81.0 & 19.9 \\
\hline & $10^{b}$ & 505 & 533 & 1.50 & 0.67 & 0.56 & 4.0 & 46 & 55 & 50 & 0.80 & 0.69 & 0.39 & 0.08 & 0.25 & 4.2 & 20.0 & 75.8 & 41.3 \\
\hline & 11 & 606 & 533 & 2.25 & 0.67 & 0.50 & 6.1 & 36 & 52 & 43 & 0.96 & 1.13 & 0.57 & 0.14 & 0.25 & 4.1 & 21.1 & 74.8 & 38.0 \\
\hline & 12 & 654 & 533 & 2.25 & 0.67 & 0.79 & 1.0 & 84 & 81 & 83 & 0.65 & 0.43 & 0.34 & 0.17 & 1.01 & 4.5 & 19.9 & 75.6 & 45.3 \\
\hline \multirow{7}{*}{2} & 13 & 92 & 533 & 1.50 & 2.00 & 5.27 & 7.1 & 77 & 39 & 52 & 1.02 & 0.17 & 0.89 & 0.14 & 0.19 & 9.2 & 24.5 & 66.3 & 35.9 \\
\hline & 14 & 122 & 533 & 1.50 & 2.00 & 3.91 & 10.1 & 66 & 34 & 46 & 1.02 & 0.23 & 0.89 & 0.14 & 0.15 & 8.4 & 24.8 & 66.8 & 34.1 \\
\hline & 15 & 146 & 533 & 1.50 & 2.00 & 2.54 & 23.5 & 41 & 25 & 32 & 1.22 & 0.36 & 0.90 & 0.11 & 0.07 & 7.8 & 28.2 & 64.0 & 29.4 \\
\hline & 16 & 191 & 513 & 1.50 & 2.00 & 2.92 & 5.8 & 55 & 34 & 42 & 1.25 & 0.30 & 0.87 & 0.15 & 0.10 & 6.3 & 23.8 & 69.9 & 27.9 \\
\hline & 17 & 240 & 533 & 2.50 & 0.67 & 0.48 & 6.7 & 43 & 60 & 50 & 0.93 & 1.32 & 0.63 & 0.21 & 0.36 & 2.8 & 17.4 & 79.8 & 35.0 \\
\hline & 18 & 268 & 533 & 2.50 & 0.67 & 0.53 & 17.1 & 20 & 37 & 27 & 1.24 & 1.51 & 0.80 & 0.15 & 0.10 & 3.6 & 20.4 & 76.0 & 26.7 \\
\hline & 19 & 313 & 533 & 2.50 & 0.67 & 0.54 & 2.0 & 70 & 76 & 72 & 0.73 & 0.88 & 0.47 & 0.23 & 0.83 & 3.4 & 19.7 & 76.9 & 41.7 \\
\hline \multirow{8}{*}{3} & 20 & 101 & 493 & 1.50 & 0.67 & 0.56 & 4.1 & 11 & 25 & 16 & 1.55 & 0.89 & 0.50 & 0.05 & 0.02 & 3.0 & 16.2 & 80.8 & 18.8 \\
\hline & 21 & 143 & 493 & 1.50 & 0.67 & 0.50 & 0.5 & 34 & 51 & 41 & 1.00 & 0.79 & 0.39 & 0.11 & 0.14 & 3.2 & 21.5 & 75.3 & 35.1 \\
\hline & 22 & 170 & 493 & 1.50 & 2.00 & 2.03 & 9.5 & 13 & 12 & 13 & 1.78 & 0.47 & 0.95 & 0.04 & 0.01 & 5.2 & 22.1 & 72.6 & 11.6 \\
\hline & 23 & 198 & 493 & 1.50 & 2.00 & 4.17 & 0.6 & 72 & 42 & 54 & 1.16 & 0.18 & 0.77 & 0.29 & 0.14 & 5.4 & 22.2 & 72.4 & 27.6 \\
\hline & 24 & 238 & 533 & 0.80 & 2.00 & 8.52 & 1.5 & 84 & 32 & 54 & 0.76 & 0.06 & 0.49 & 0.05 & 0.13 & 11.0 & 24.9 & 64.1 & 39.5 \\
\hline & 25 & 268 & 533 & 0.80 & 2.00 & 2.42 & 9.0 & 35 & 21 & 25 & 1.22 & 0.21 & 0.50 & 0.03 & 0.03 & 7.1 & 23.4 & 69.6 & 31.0 \\
\hline & 26 & 292 & 513 & 0.80 & 0.67 & 0.61 & 5.5 & 9 & 17 & 13 & 1.25 & 0.47 & 0.29 & 0.02 & 0.01 & 3.1 & 16.1 & 80.7 & 27.9 \\
\hline & 27 & 318 & 513 & 0.80 & 0.67 & 0.61 & 0.7 & 50 & 54 & 54 & 0.73 & 0.34 & 0.21 & 0.04 & 0.17 & 2.9 & 15.5 & 81.6 & 45.8 \\
\hline
\end{tabular}

Note: $\mathrm{b}$ - baseline condition. 
Figure 1

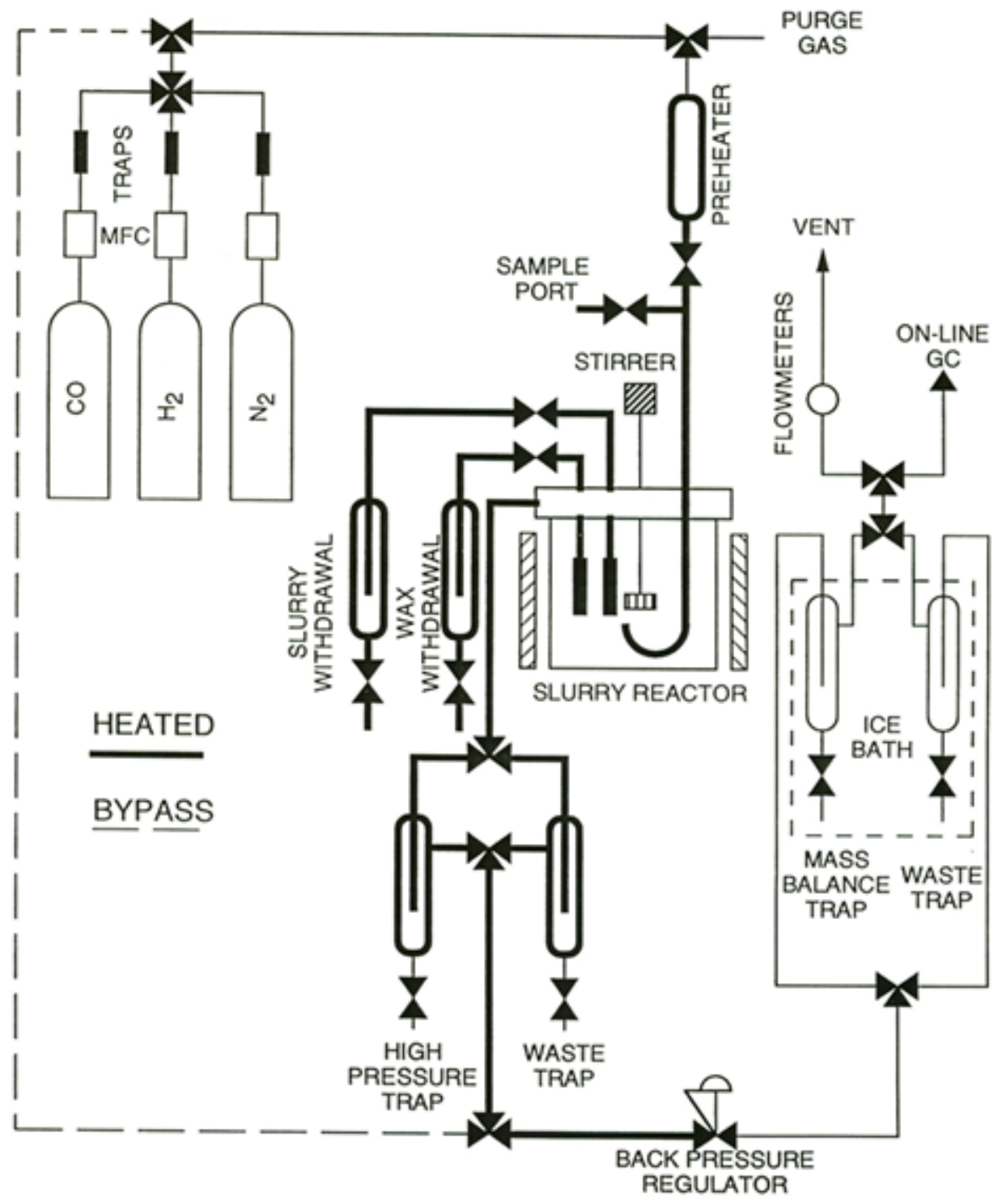


Figure 2a

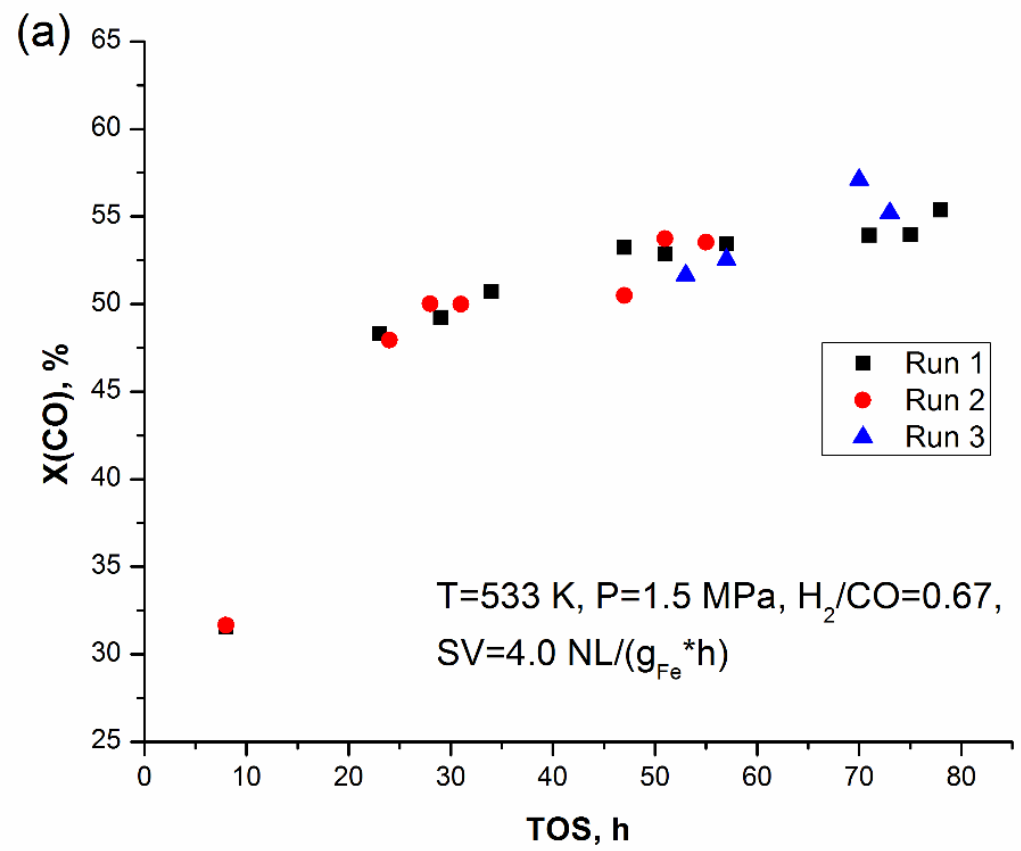

Figure 2b

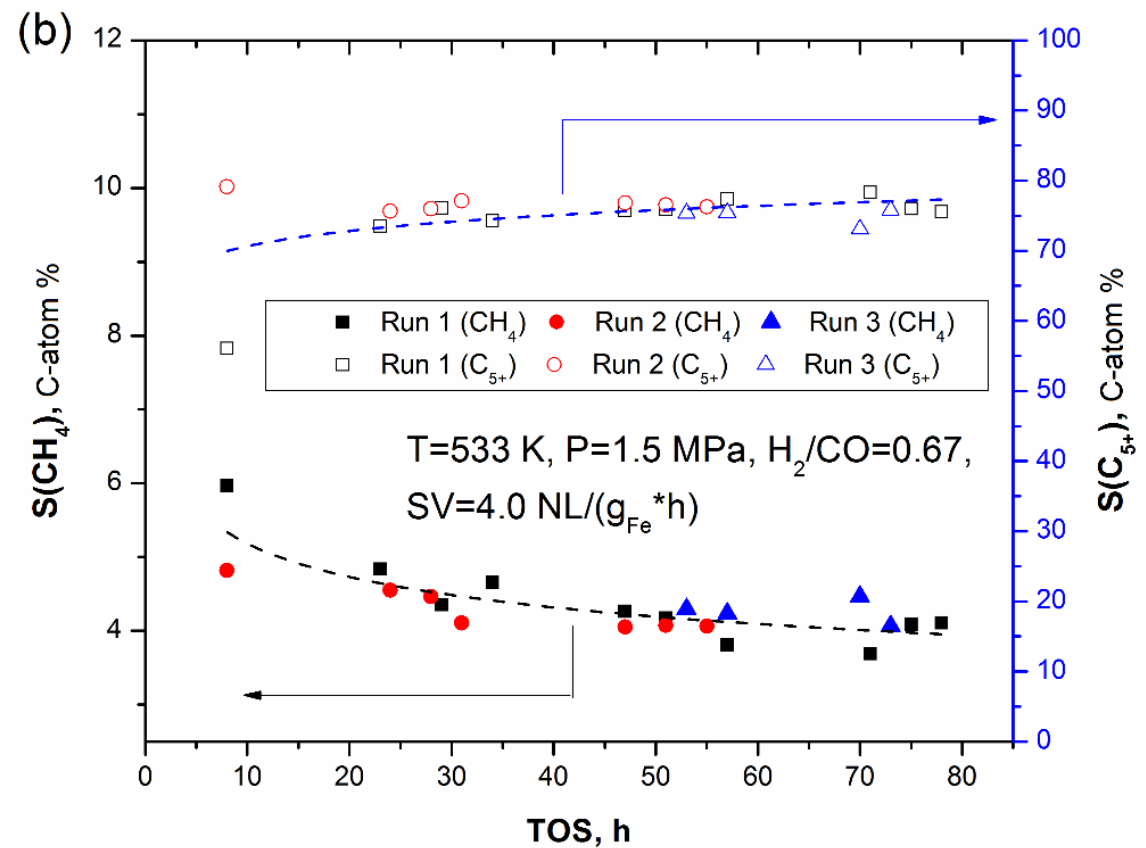


Figure 3a

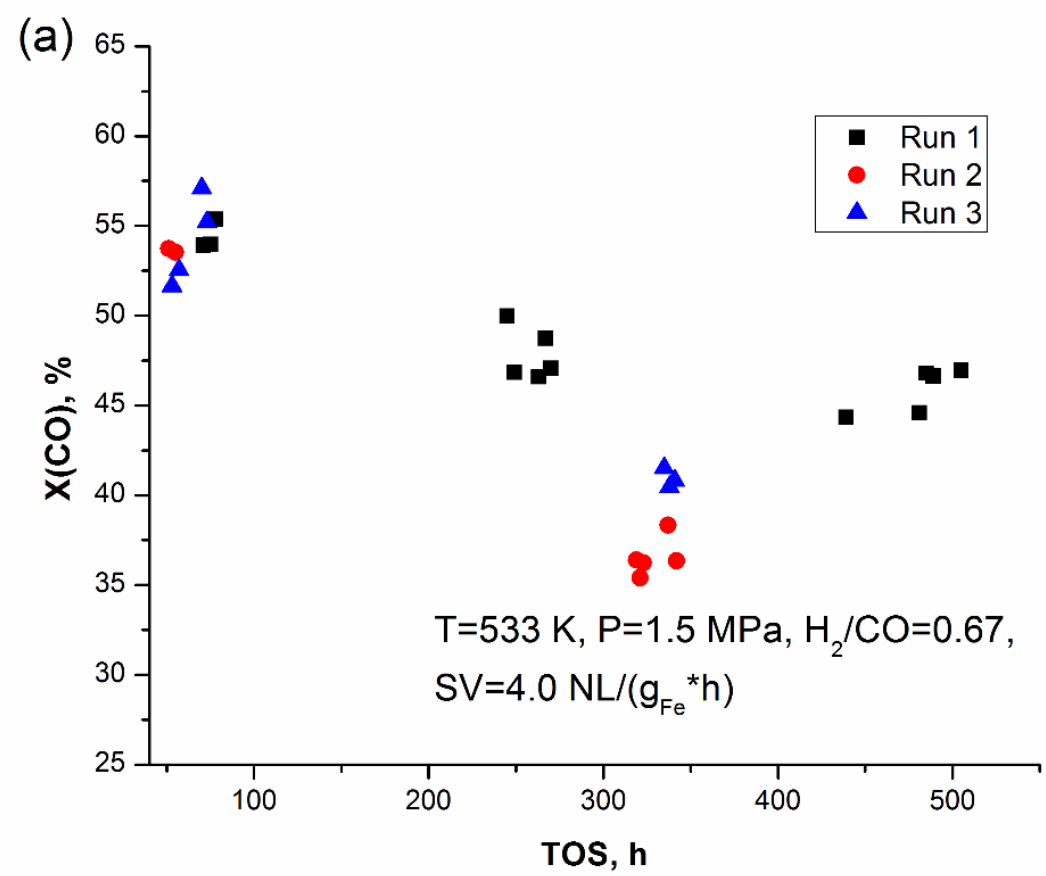

Figure $3 b$

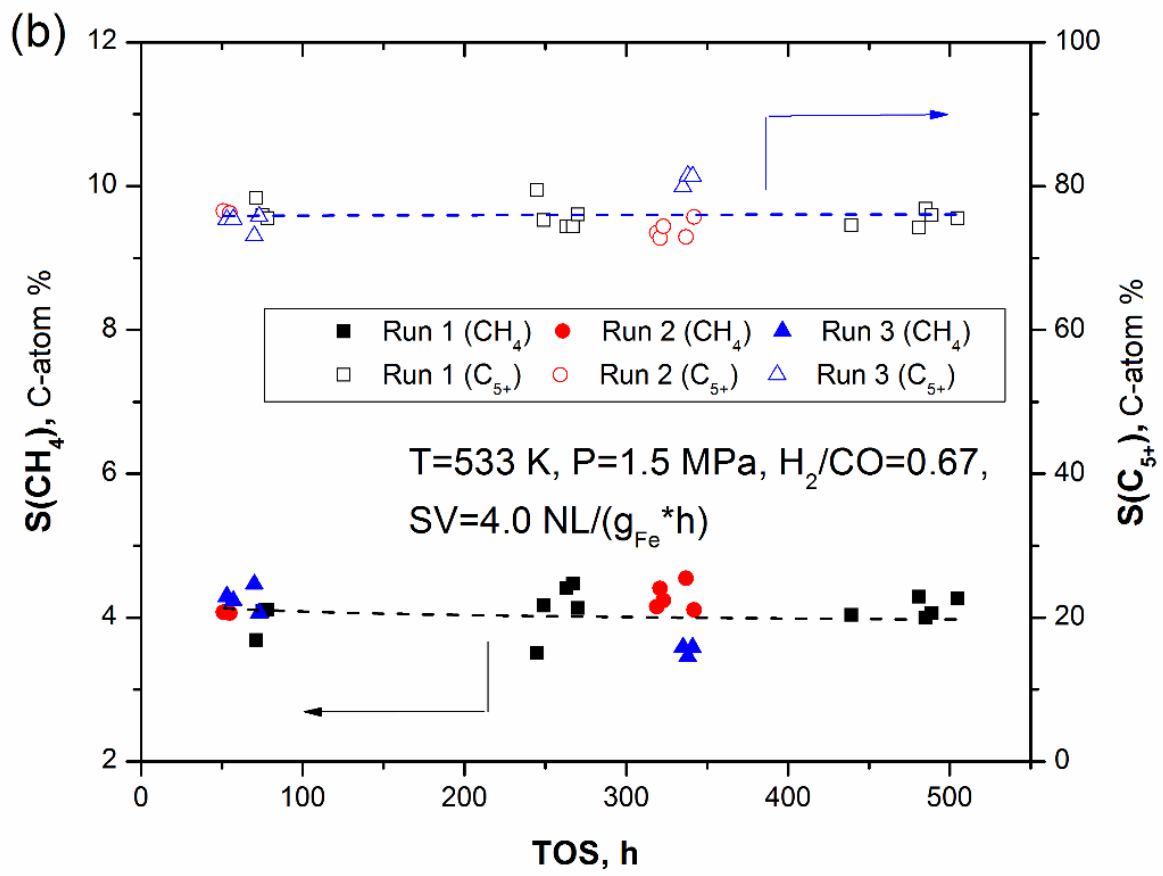


Figure 4a

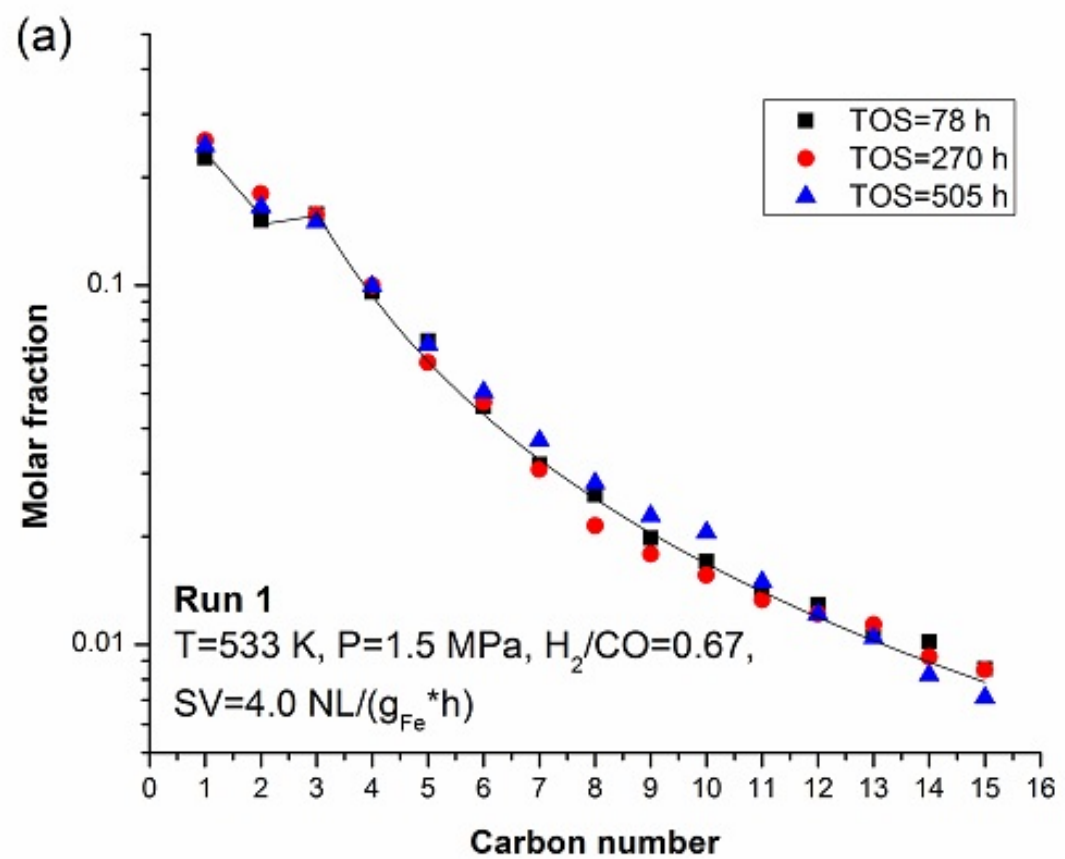

Figure 4b

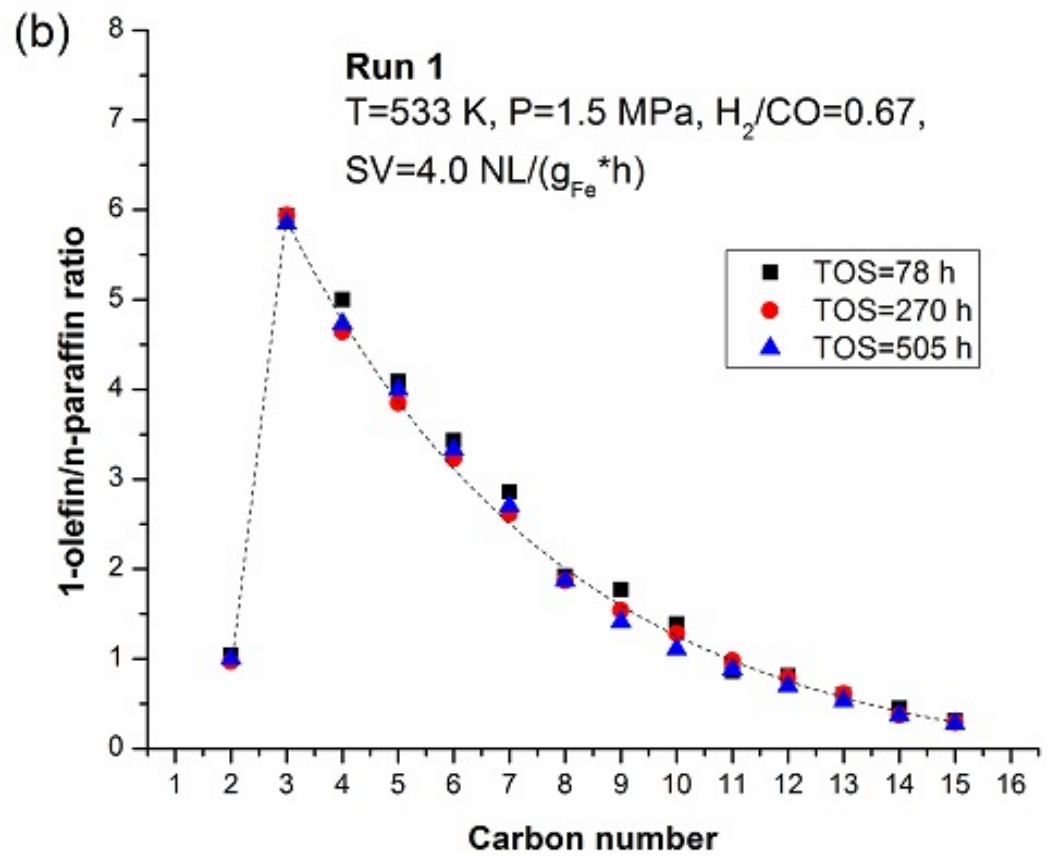


Figure 5a

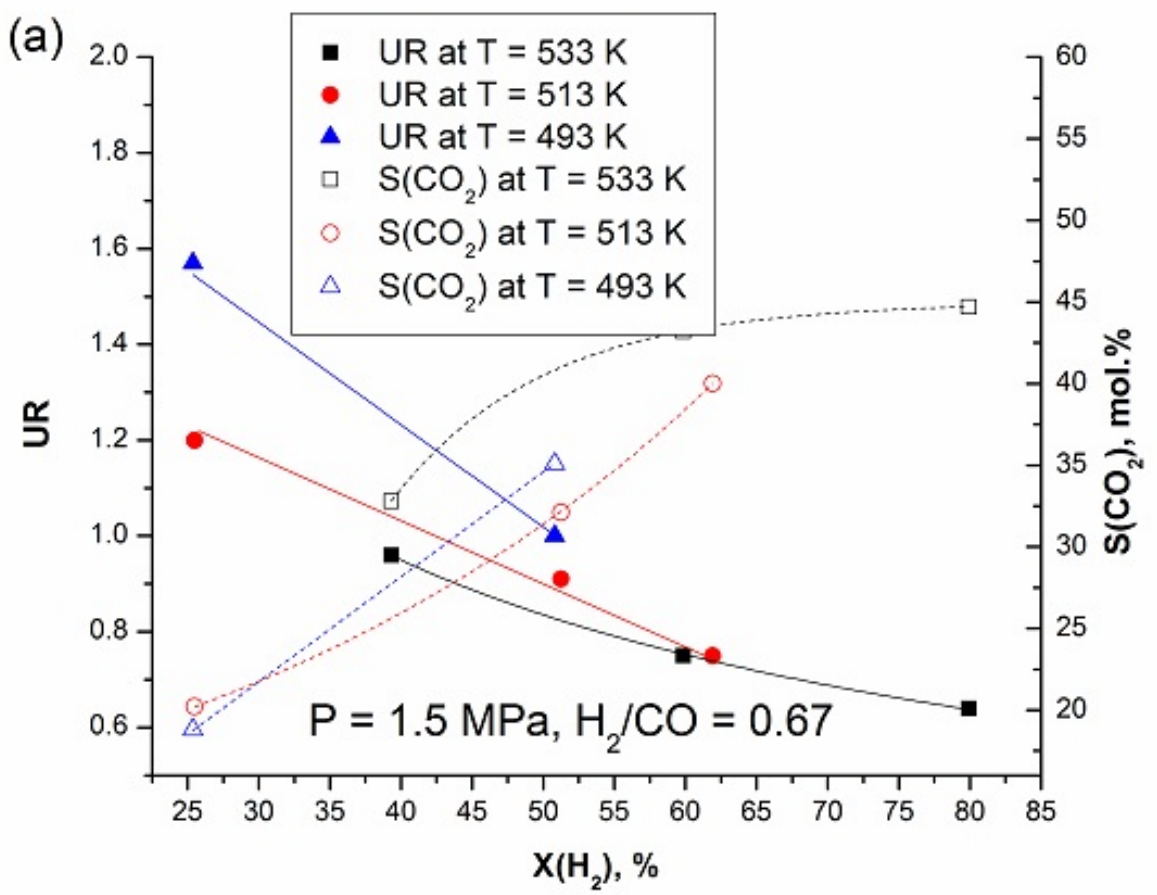

Figure 5b

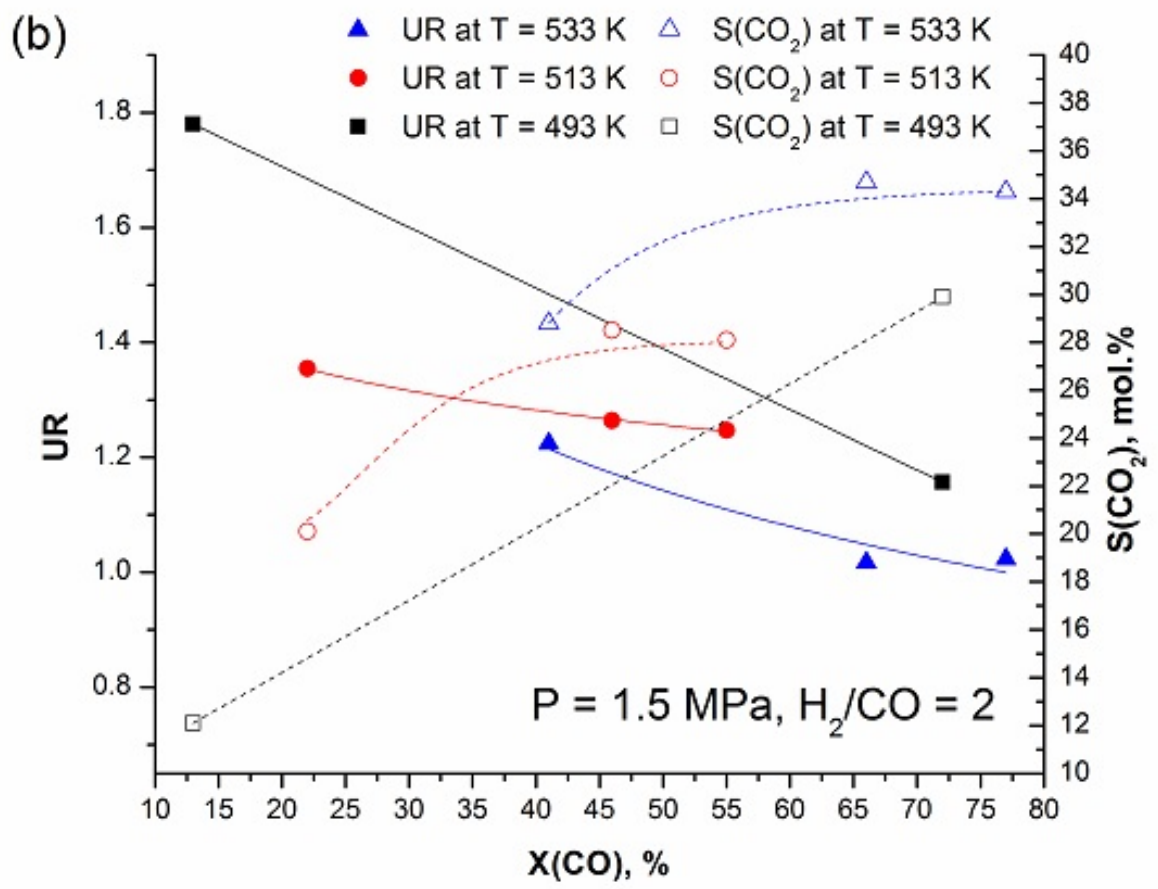


Figure 6

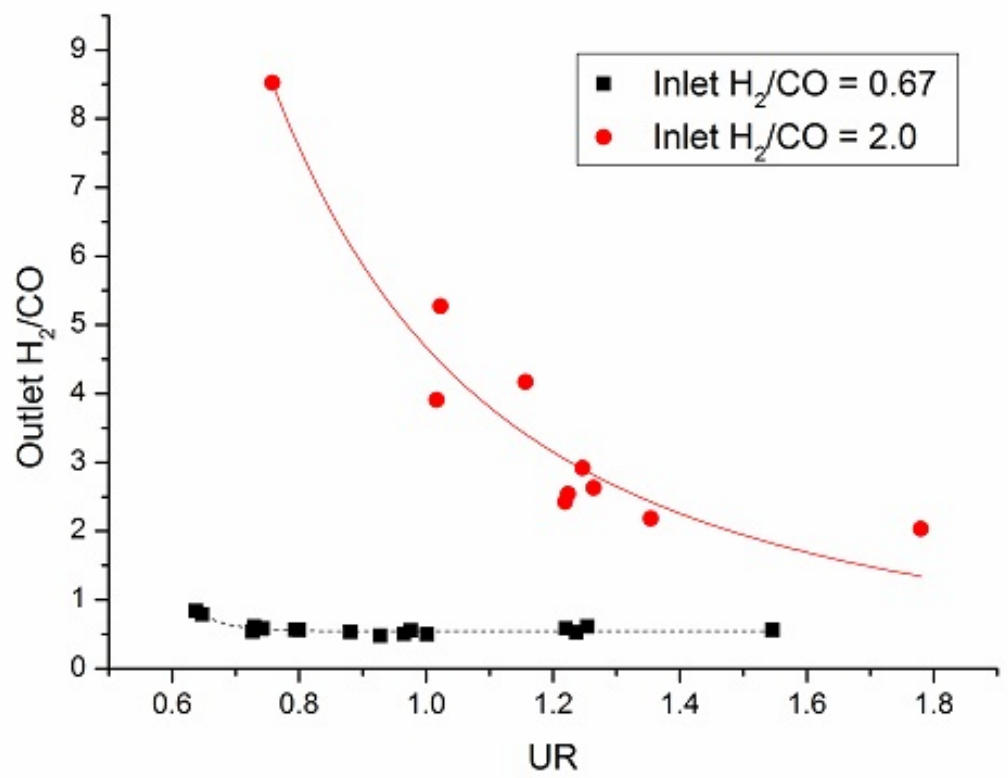


Figure 7a

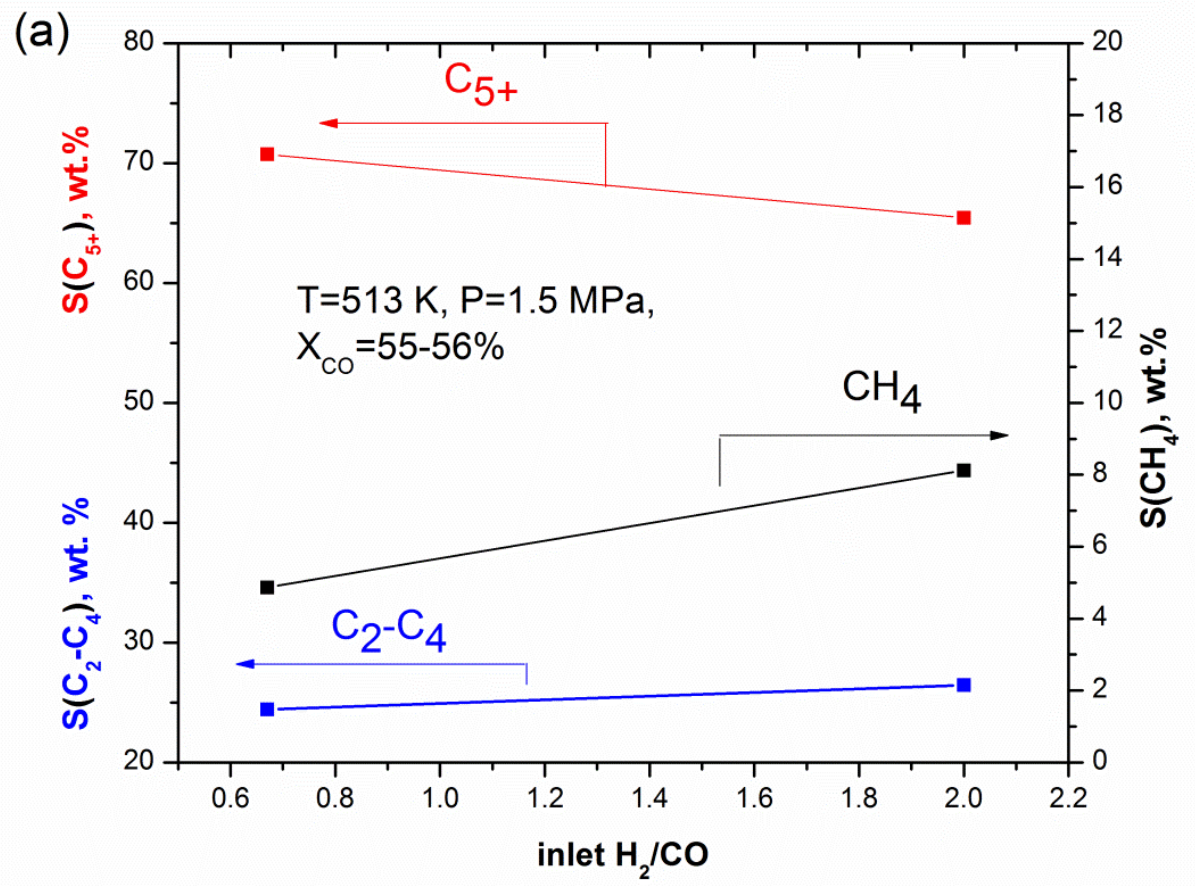

Figure 7b

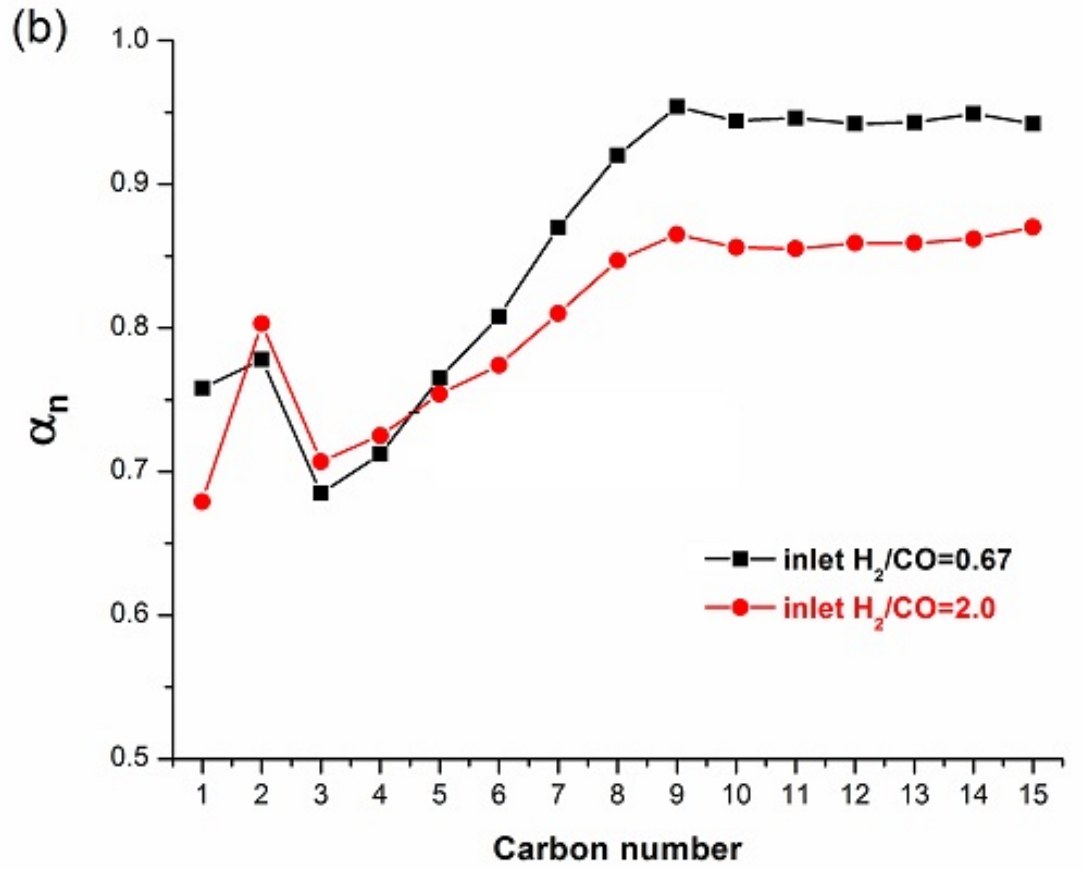


Figure 7c

(c)

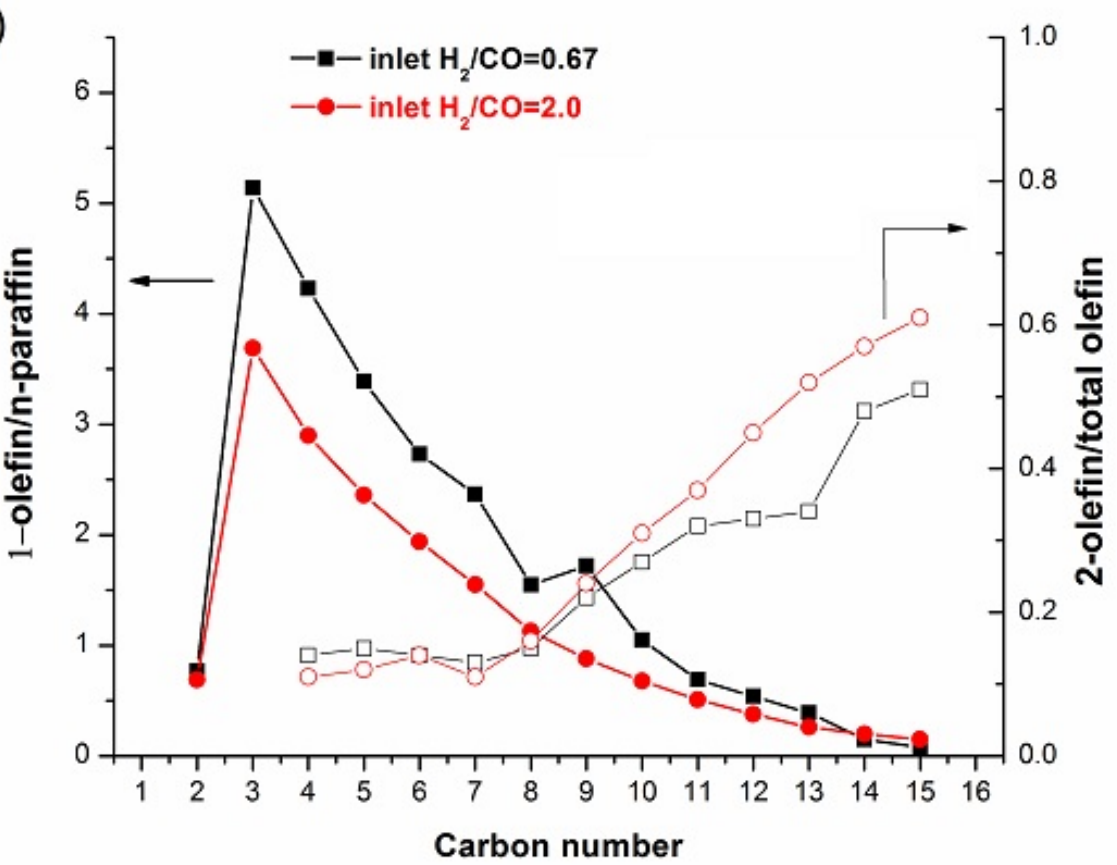


Figure 8a

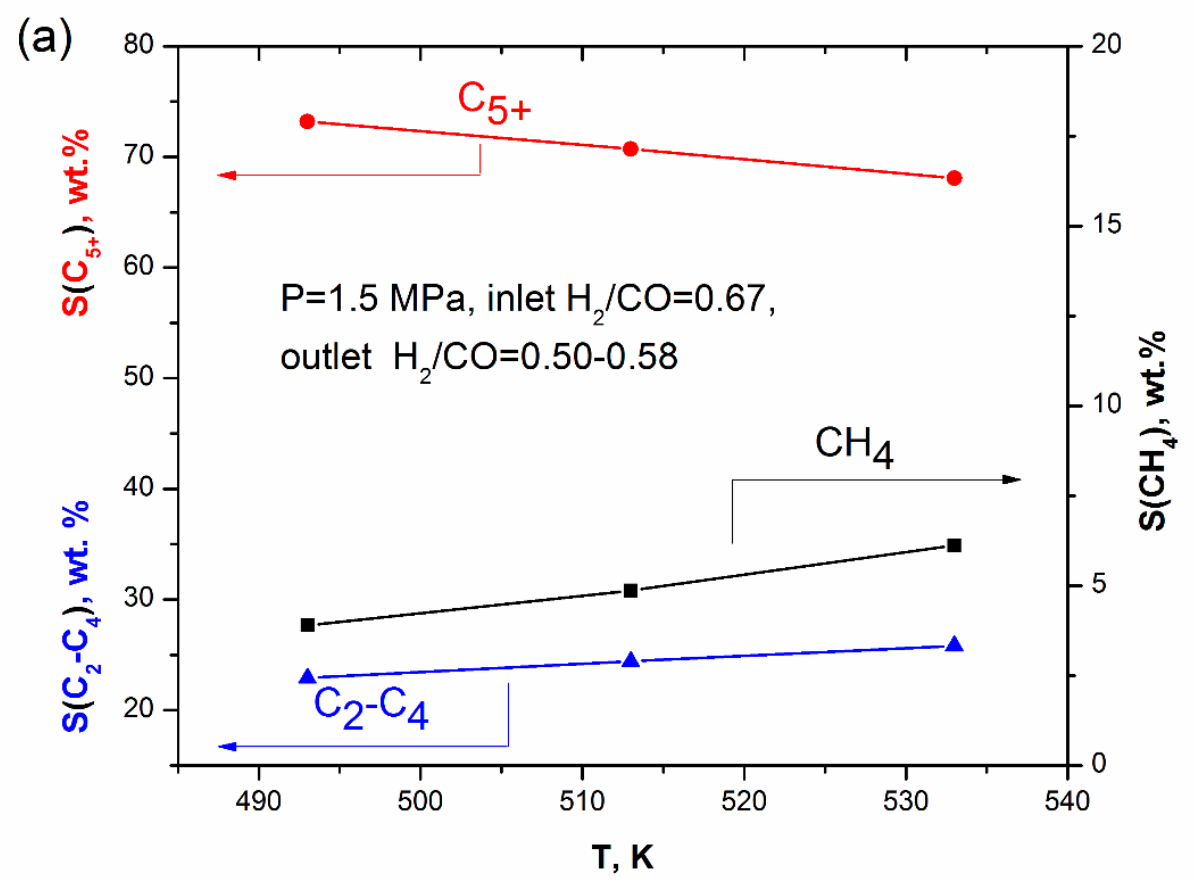

Figure 8b

(b)

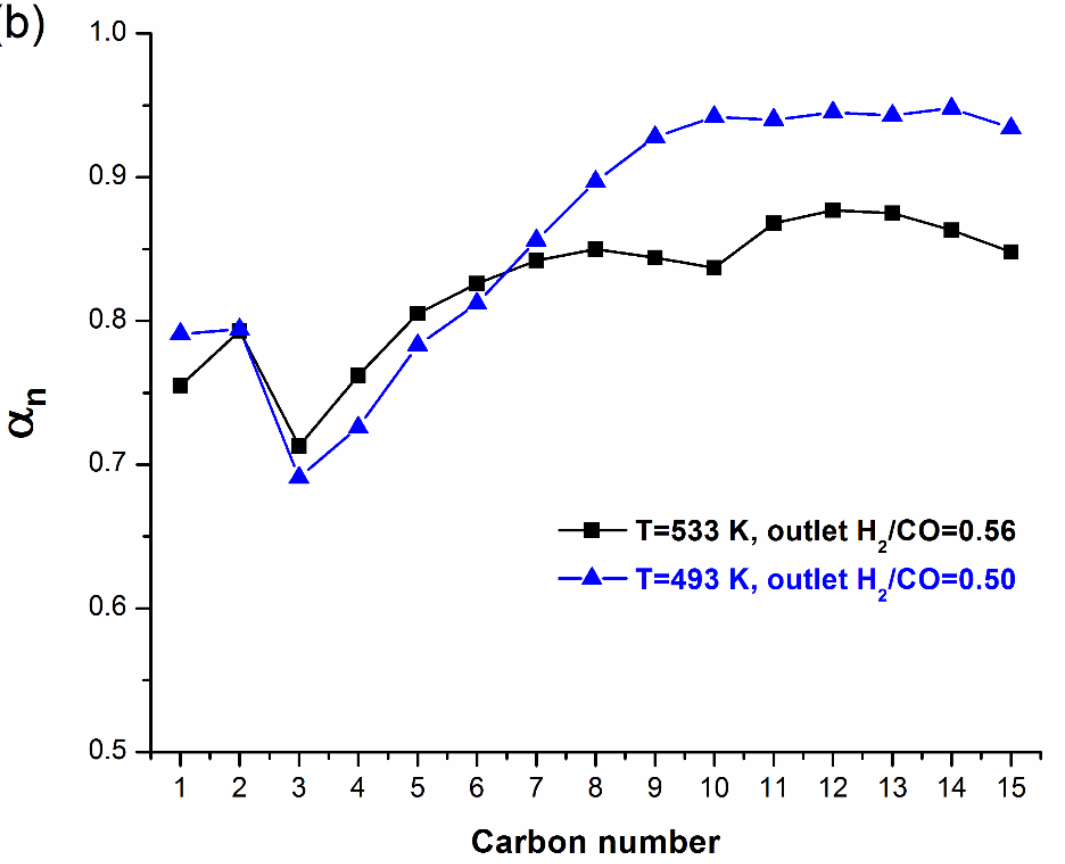


Figure 8c

(c)

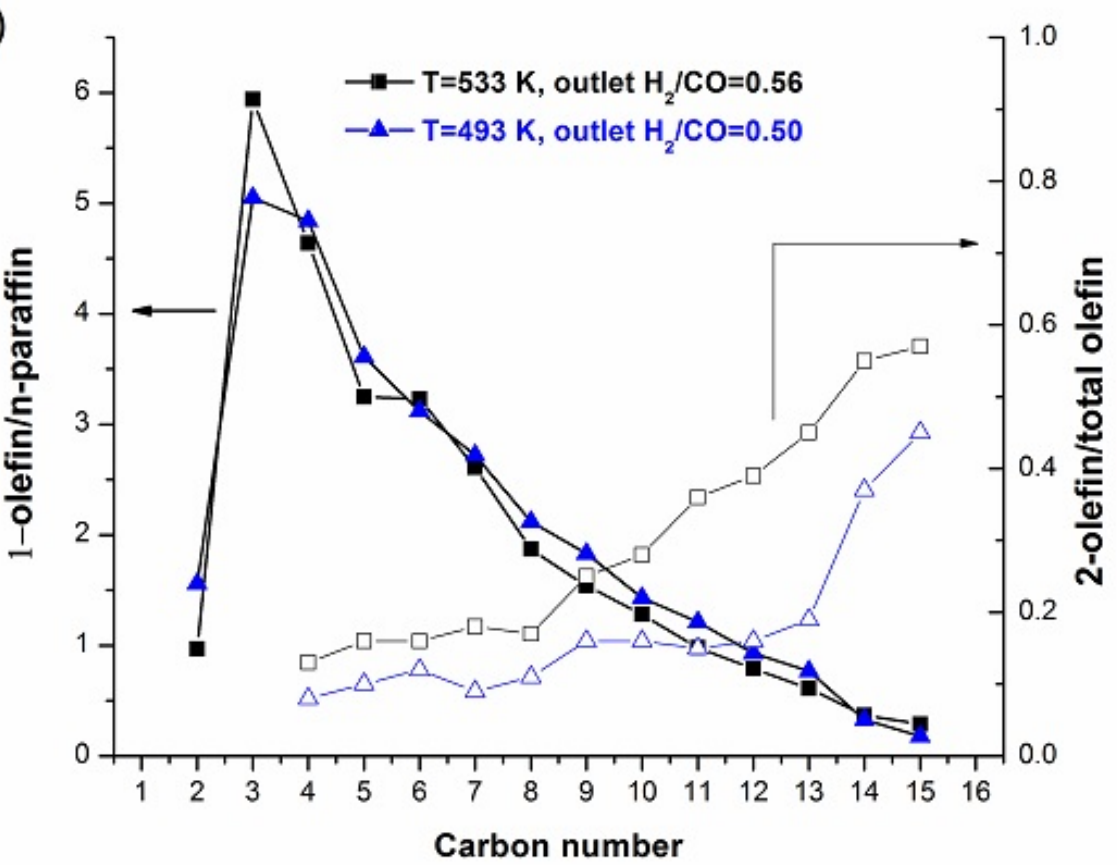


Figure 9a

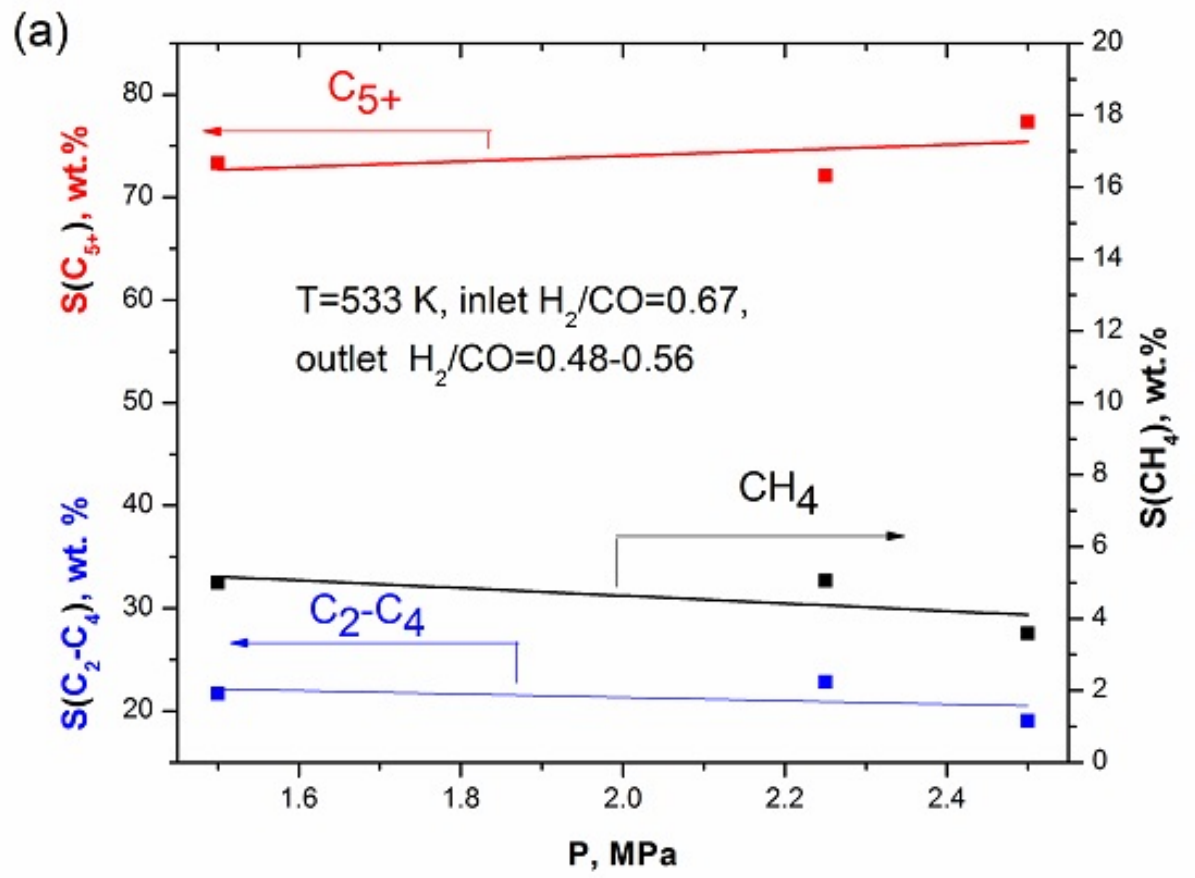

Figure 9b

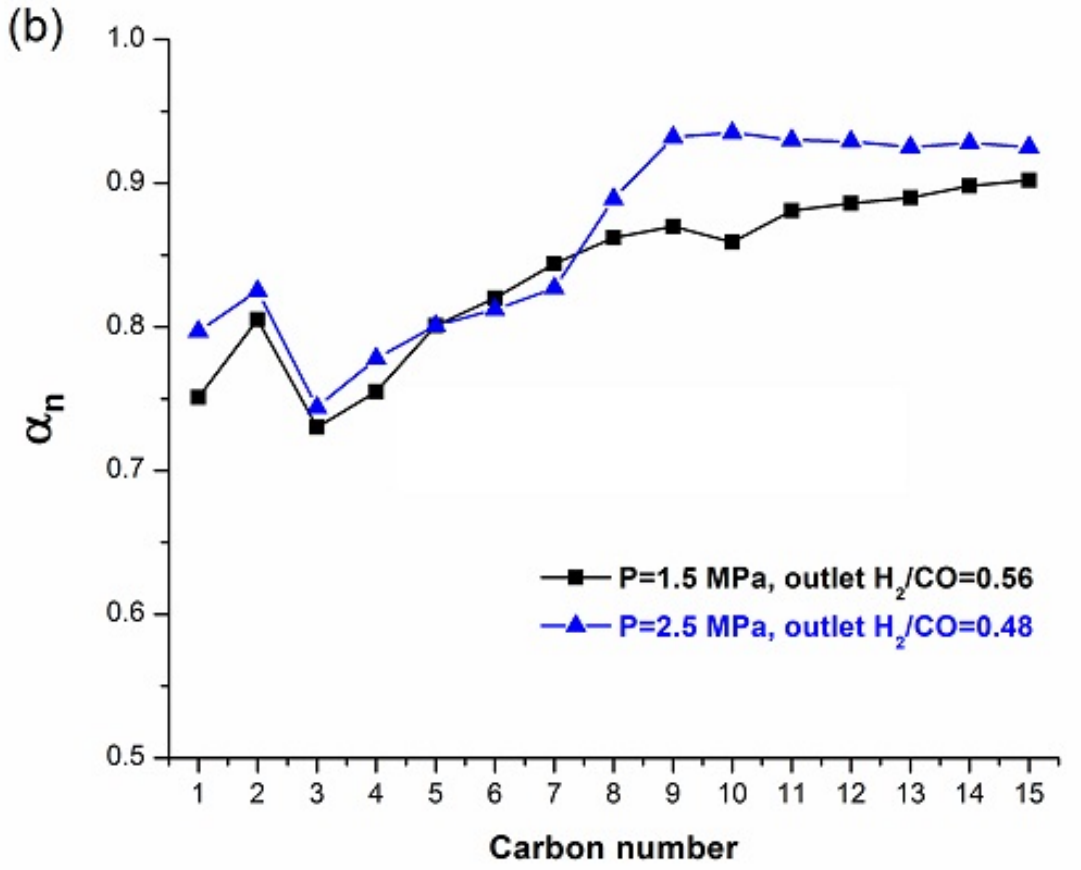


Figure 9c

(c)

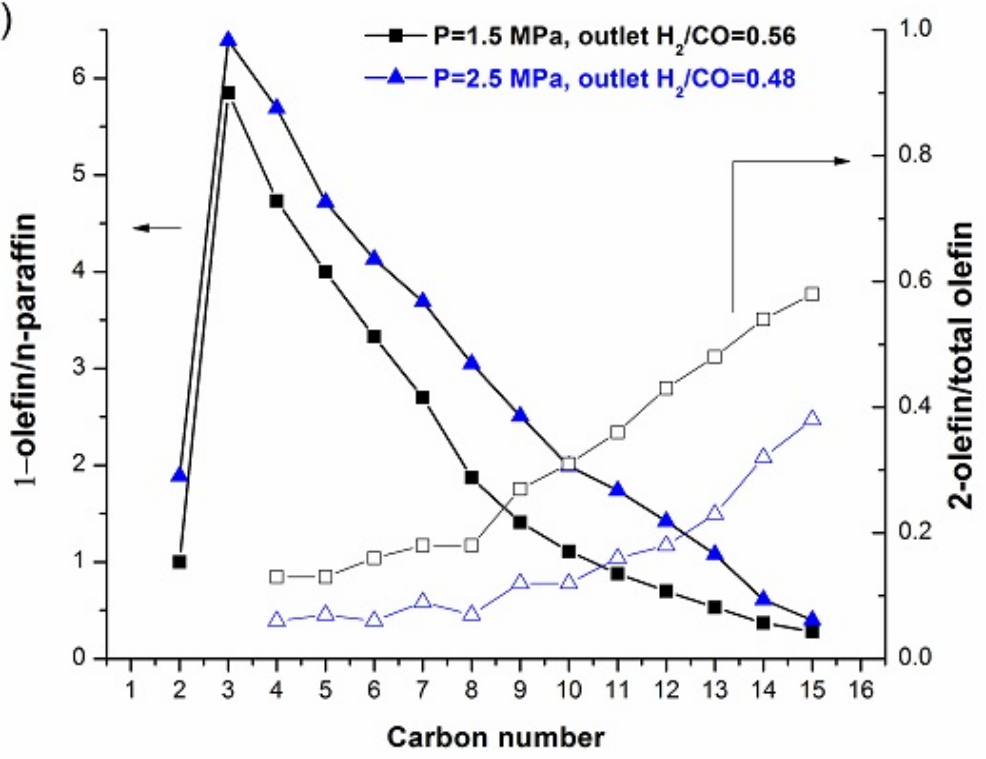


Figure 10a

a)

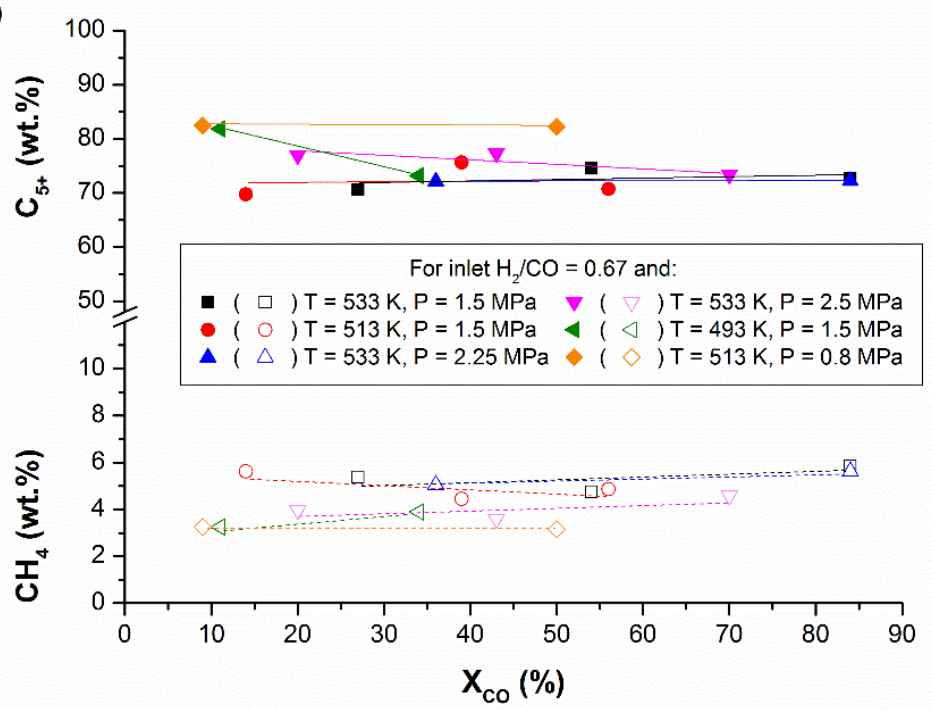

Figure 10b

b)

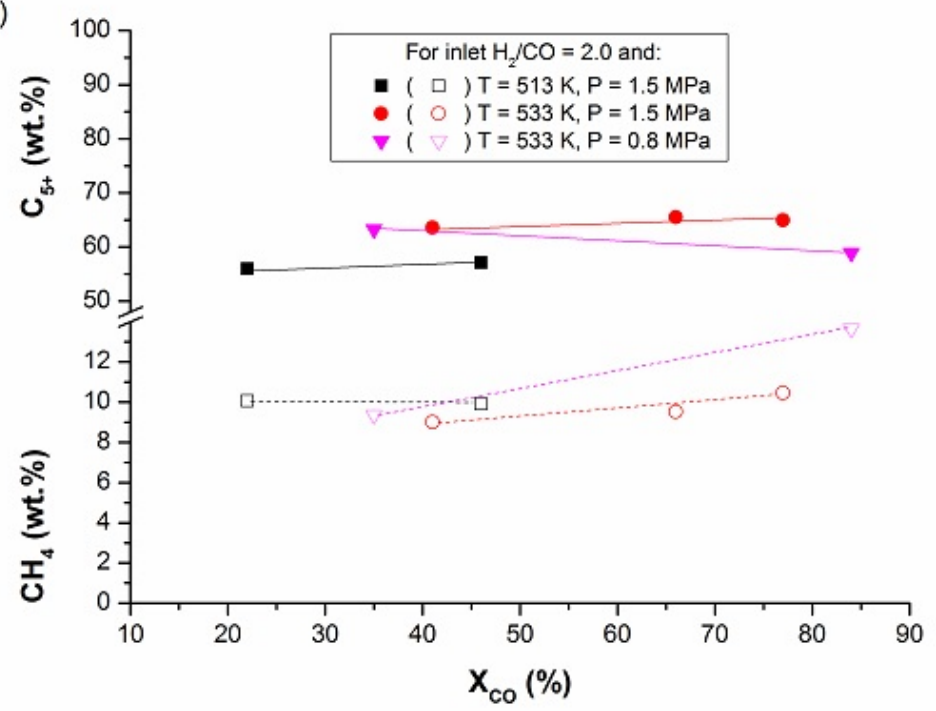


Figure 11a

(a)

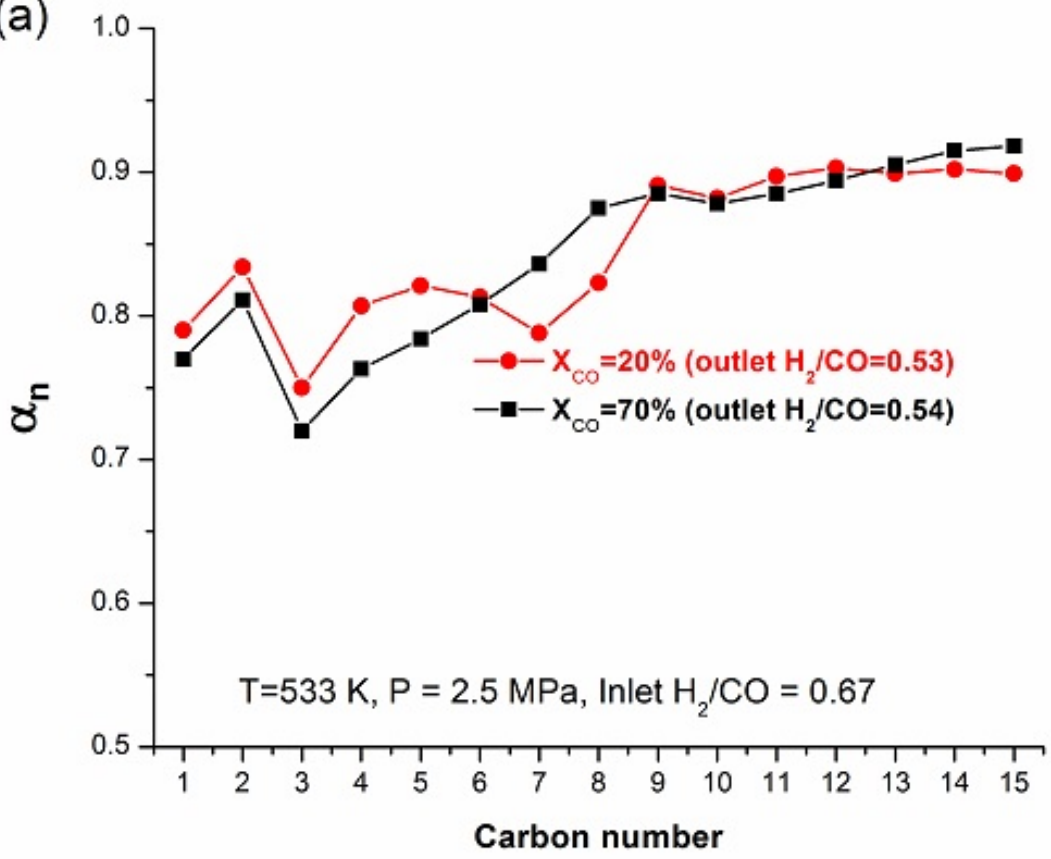

Figure 11b

(b)

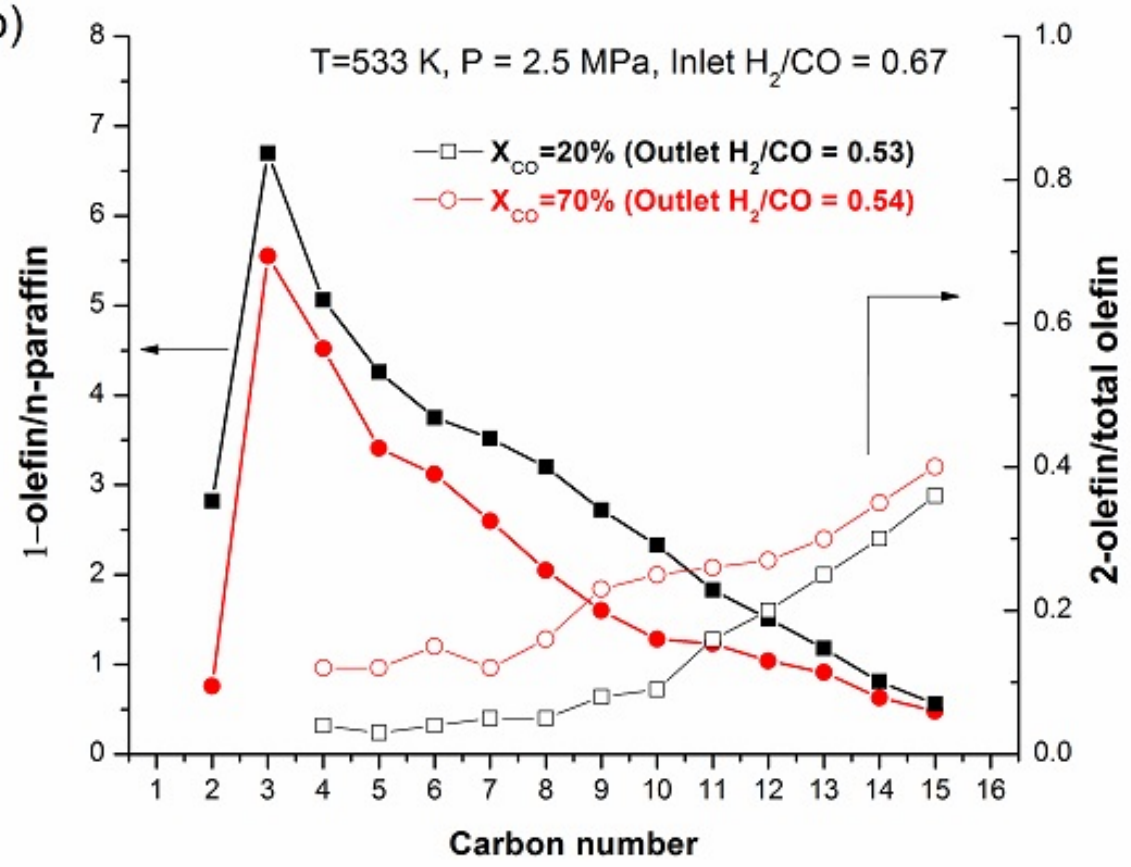


Figure 12a

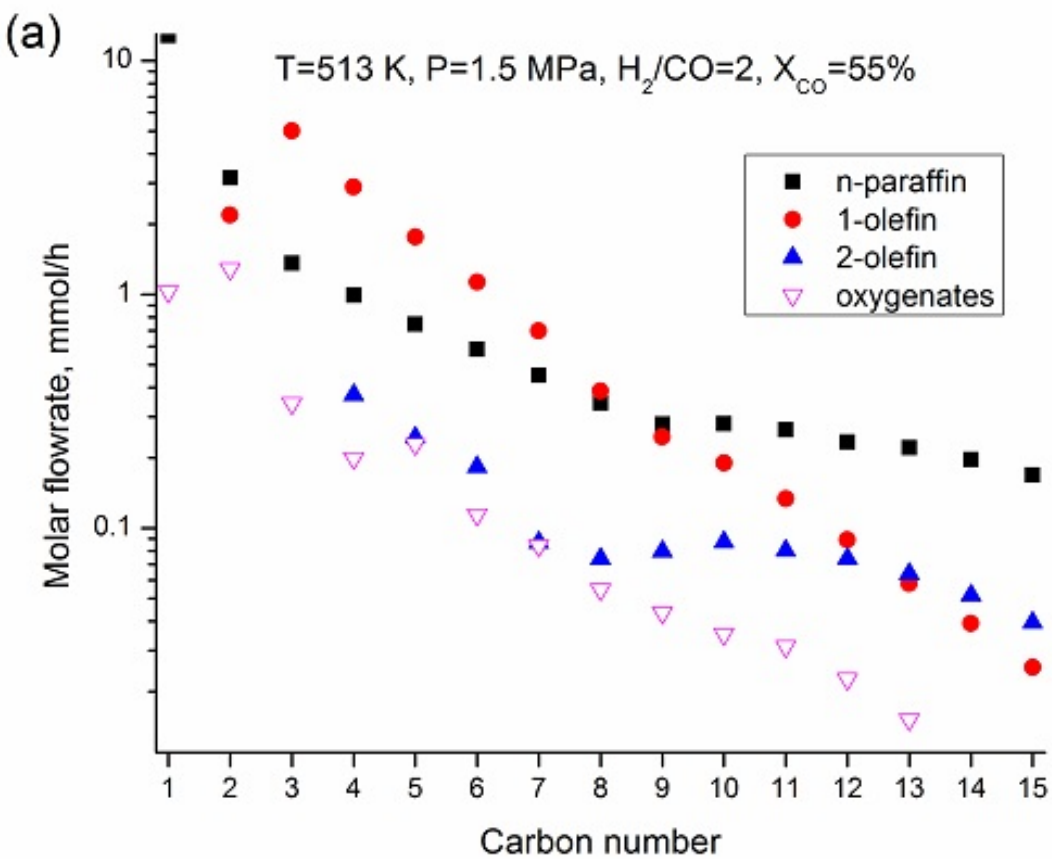

Figure 12b

(b)

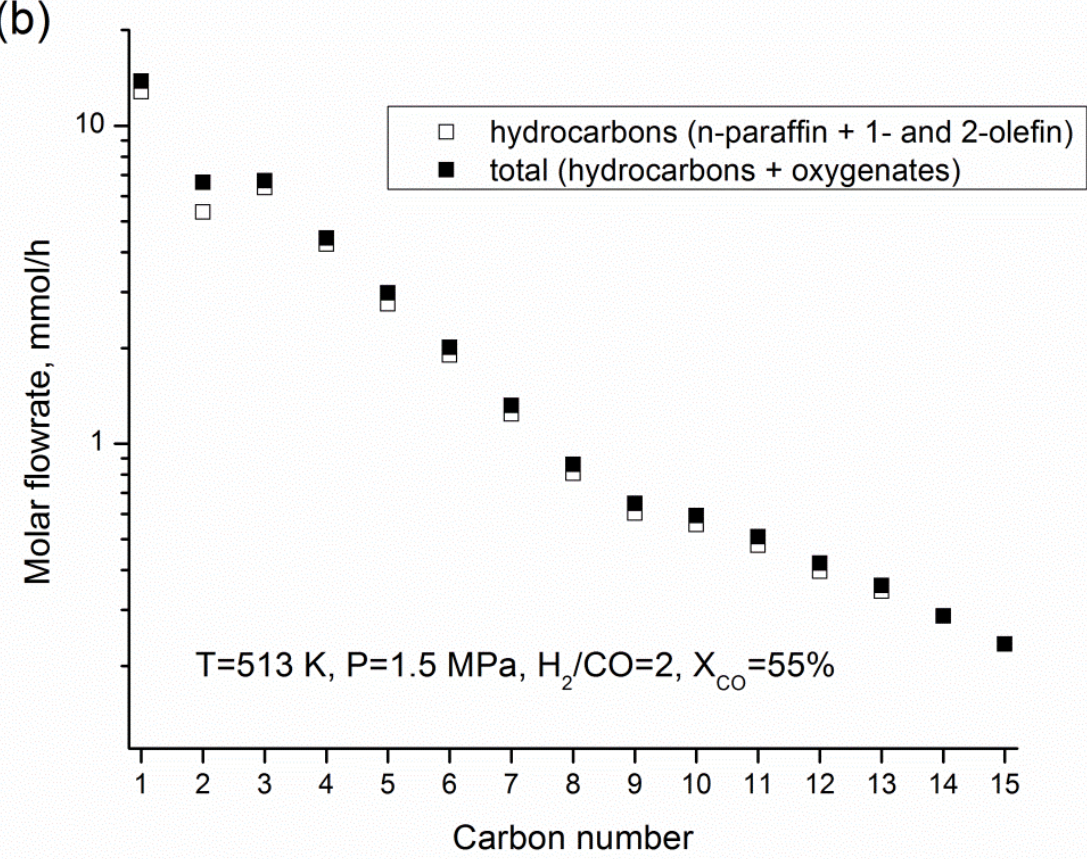


Figure 13

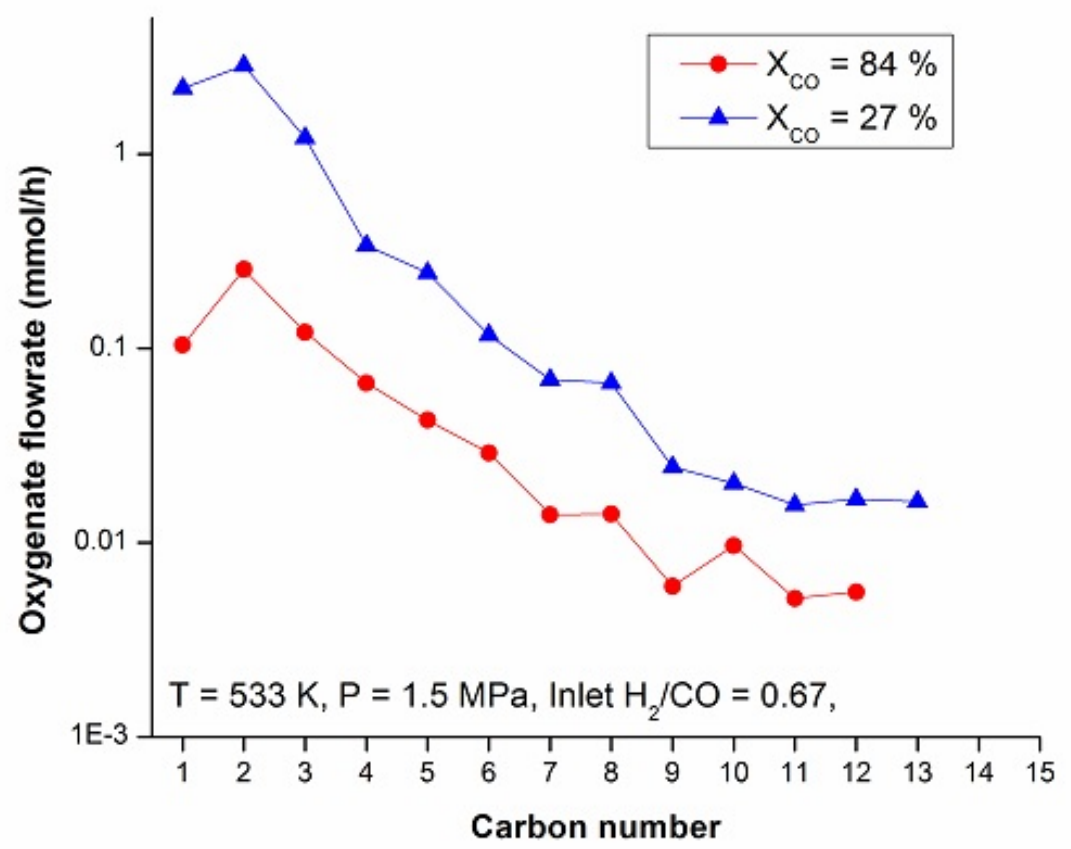


Figure 14a

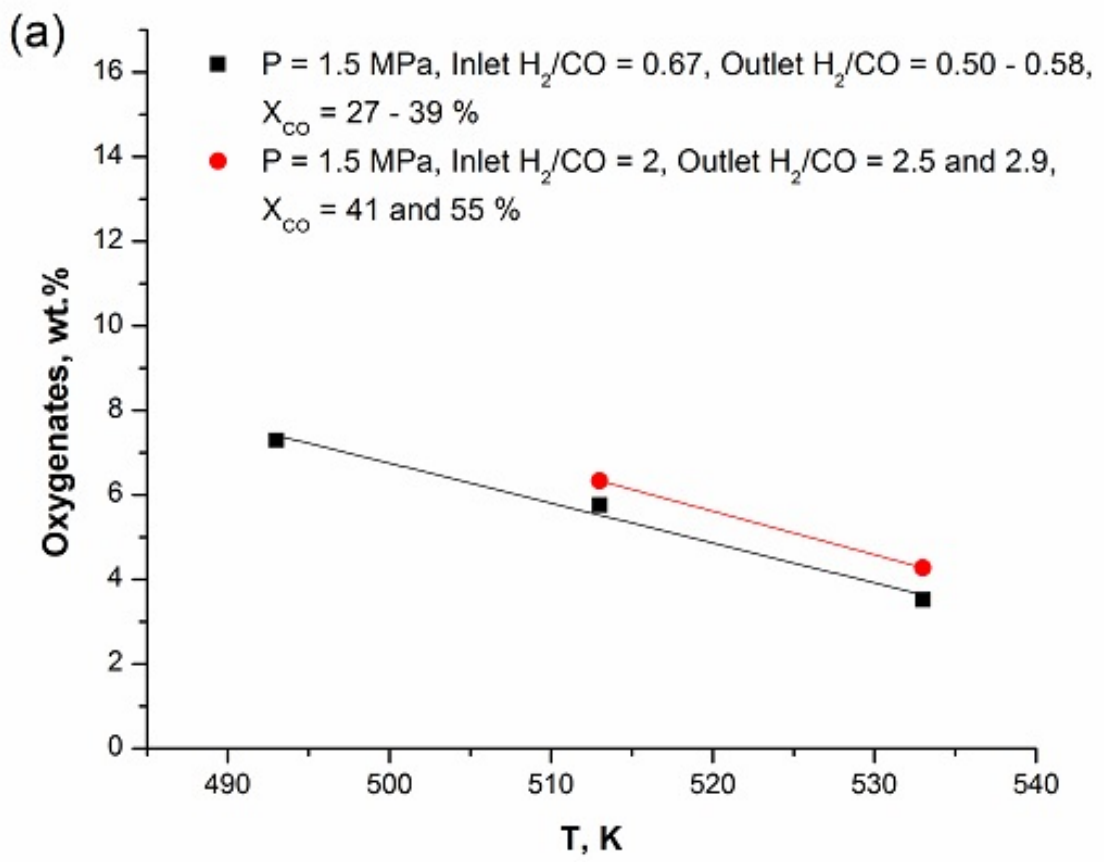

Figure 14b

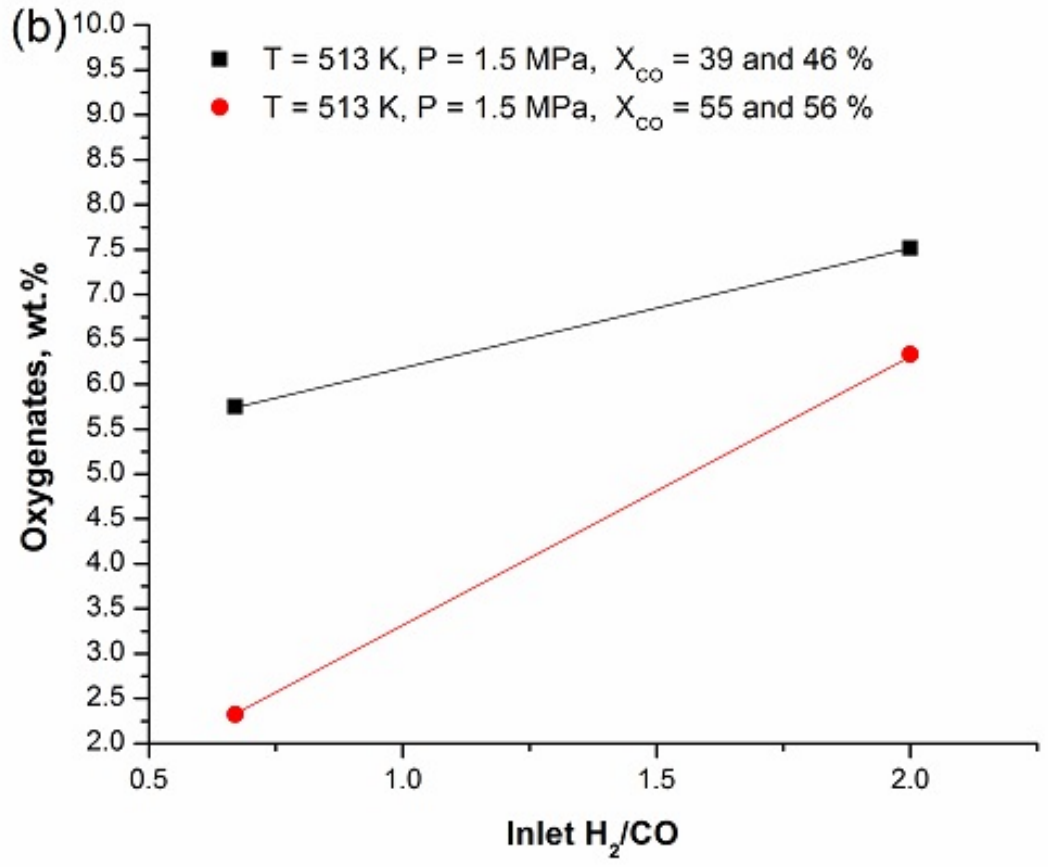


Component carbon number distribution

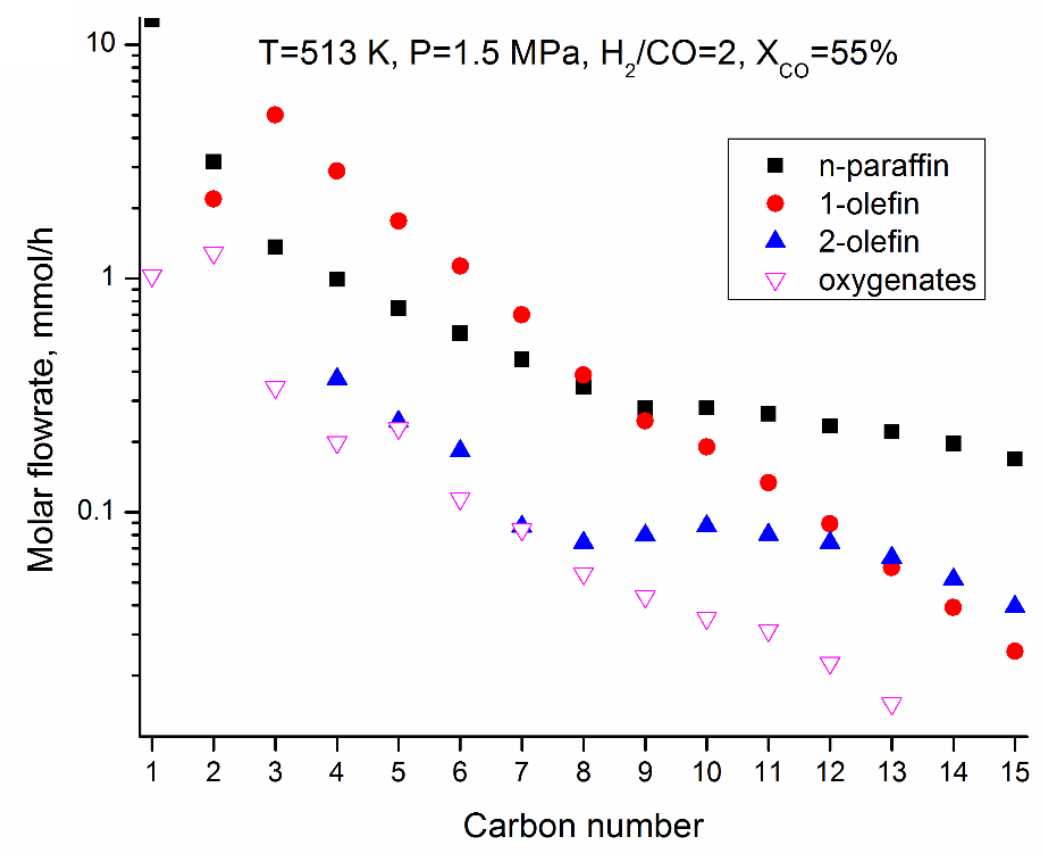

